\title{
Clinical Relevance of Nanoparticle Induced Hyperthermia for Drug Delivery and Treatment of Abdominal Cancers
}

\author{
Nicole H. Levi-Polyachenko*,1 and John H. Stewart IV ${ }^{2}$ \\ ${ }^{I}$ Wake forest University Health Sciences, Plastic and Reconstructive Surgery Department, Winston-Salem, NC, USA \\ ${ }^{2}$ Wake Forest University Health Sciences, Department of General Surgery, Section on Surgical Oncology, \\ Winston-Salem, NC, USA
}

\begin{abstract}
The aim of this review is to introduce the reader to the potential clinical utility for the delivery of chemotherapy in the context of nanoparticles. We will present traditional methods of hyperthermia and then focus on the clinical technique for using intraperitoneal hyperthermic chemoperfusion for the treatment of peritoneal surface dissemination of colorectal cancer. Cellular mechanisms of hyperthermia as well as clinically effective chemotherapeutic agents are discussed. In the past decade carbon and metal nanoparticles have been explored for their ability to induce hyperthermia; however, many of these studies examine nanoparticles for tumor ablation at high temperatures. There are currently few studies that evaluate mild hyperthermia (below $43^{\circ} \mathrm{C}$ ) generated by nanoparticles to enhance the delivery of chemotherapeutic agents. The fundamentals for generation of hyperthermia from carbon and metal nanoparticles is discussed as are the limitations and benefits of specific nanoparticles with chemotherapeutic agents. This review will show that there is significant potential for the use of nanoparticles to induce hyperthermia and increase the delivery of chemotherapeutic agents for treatment of colorectal cancer and other peritoneal disease.
\end{abstract}

Keywords: Hyperthermia, intraperitoneal chemoperfusion, nanoparticles.

\section{CLINICAL BACKGROUND}

Cancer is the second leading cause of death in the United States [1]. Current treatments include surgical removal, chemotherapy, radiation, and ablation therapies. Statistics from the International Agency for Research on Cancer cite that 10.9 million cases of cancer are diagnosed every year, with a $61.9 \%$ incidence of death [1]. Unfortunately, the more underdeveloped regions of the world suffer mortality rates as high as $77.9 \%$, whereas societies with more economic resources have mortality rates around $40 \%$ [2]. Approximately 150,000 cases of colorectal cancer are diagnosed in the United States every year and approximately one third of the patients will die from metastatic disease [3]. Refinements in treatment regimes are made according to clinical response. Although intravenous chemotherapy delivery is beneficial for many tumor types, systemically delivered agents often do not reach peritoneal metastases in high enough concentrations to be very effective; therefore regional delivery is preferred for the treatment of peritoneal metastasis [4].

Traditional Methods for Use of Hyperthermia and Chemotherapy

Clinical hyperthermia can be delivered to the whole body, regionally (limbs) or locally (tissues) by methods such as warming blankets, electrically resistive implants, microwaves, radio waves, perfusion of warm fluids, ultrasound, infrared light, application of alternating magnetic fields to ferrofluids, or stimulation carbon, metal, or metal oxide

*Address correspondence to this author at the Wake forest University Health Sciences, Plastic and Reconstructive Surgery Department, WinstonSalem, NC, USA; Tel: 336-713-8052; Fax: 336-713-6524;

E-mail: nlevi@wfubmc.edu nanoparticles. For example, whole body hyperthermia, although rarely used, can benefit patients who present with widely disseminated diseases such as malignant melanoma or sarcomas. Regional hyperthermia is often delivered to the abdomen or limbs and can benefit patients with regional metastasis of cervical, ovarian, bladder, prostate, lung, mesothelioma, appendicial and colorectal cancers. Local hyperthermia is optimal for small tumors $<3 \mathrm{~cm}[4,5]$. One of the main challenges of local and regional hyperthermia is development of a homogeneous temperature distribution throughout the tissue. A measure of the tissue distribution of hyperthermia is cumulative equivalent minutes (CEM). For example, CEM $43^{\circ} \mathrm{C}$ T90 refers to the time for the temperature of $43^{\circ} \mathrm{C}$ to be reached in $90 \%$ of the target tissue [5]. Based on plots of temperature-dependent cell survival, temperature increases of $1^{\circ} \mathrm{C}$ over the threshold of $43^{\circ} \mathrm{C}$ leads to doubling of cell death (Fig. 1) [5]. Hyperthermia can increase drug transport across membranes and accelerate the damage of proteins and DNA as well as generation of free oxygen radicals $[5,6]$. Although it is most beneficial to deliver hyperthermia and chemotherapy simultaneously, delivery of some chemotherapeutic agents prior to delivery of hyperthermia allows for drug metabolism and cytotoxic effects to be enhanced with the onset of hyperthermia [5]. Hyperthermia also offers some potential for overcoming drug resistance by manipulating heat shock proteins HSP27, HSP70, and HSP90, which are associated with drug resistance, particularly platinum drugs [7].

\section{Direct Effects of Hyperthermia on Cancer}

Hyperthermia is a superior adjunct for drug delivery as it aids in drug delivery by multiple mechanisms. Hyperthermia leads to increased blood flow; thus higher concentrations of 
drugs will be localized to a tumor in the context of hyperthermia. On a cellular level, hyperthermia increases permeability of cell membranes, thus allowing higher intracellular concentrations of chemotherapy [6]. In addition, hyperthermia enhances DNA damage, and the mitochondrial machinery will be more susceptible to disruption by drugs targeting mitochondria.

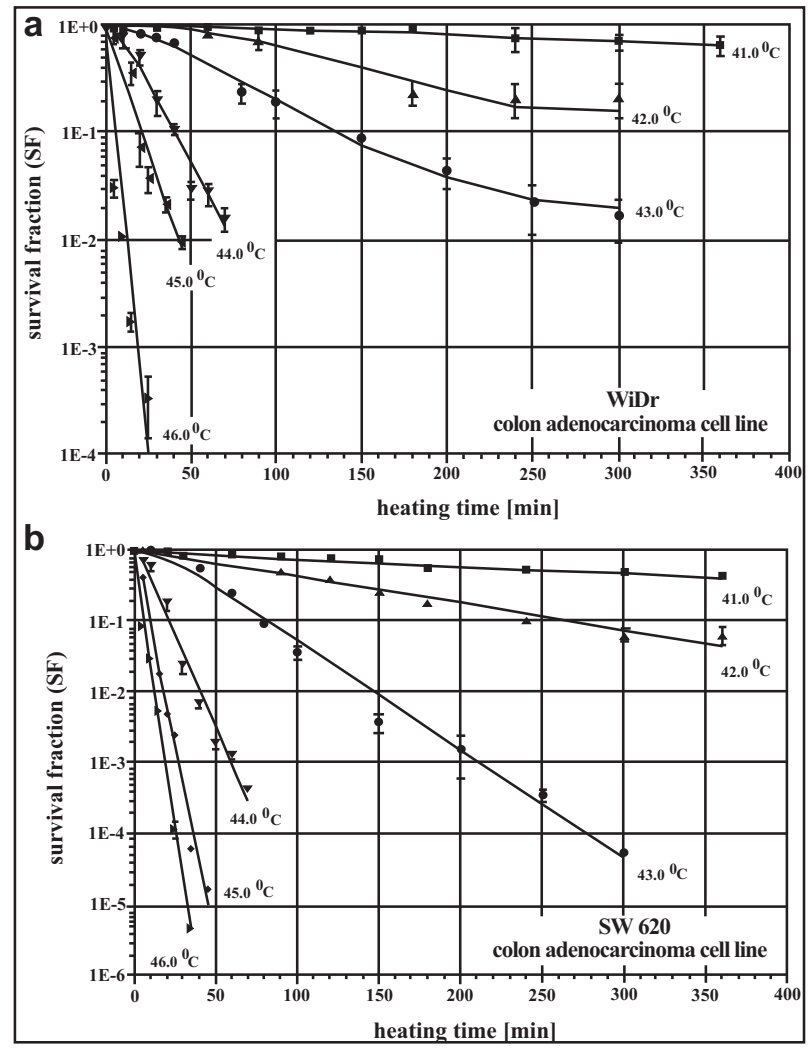

Fig. (1). Effect of various hyperthermic temperatures on colorectal cancer cells. Temperatures above $42^{\circ} \mathrm{C}$ are the most effective for cell killing. Reproduced from [8].

Temperatures above $45^{\circ} \mathrm{C}$ which produce irreversible cell damage are referred to as thermal ablation techniques. Thermal ablation treatments have a specific region of cell kill bordered by regions suffering less intense hyperthermia which may not be sufficient for cell kill and may instead upregulate HSPs. The induction of HSPs around the area of thermal ablation may lead to more aggressive tumor recurrence [8]. Monitoring upregulation of HSPs according to hyperthermia and/or drug treatments can be used to evaluate the most effective treatment parameters. For example, it is expected that mild hyperthermia at $42^{\circ} \mathrm{C}$, which is clinically used for HIPEC therapies, will not increase HSP expression compared to treatment at $37^{\circ} \mathrm{C}$.

\section{Synergistic Effects of Hyperthermia with Chemotherapy}

Heated Intraperitoneal Chemotherapy (HIPEC) delivers drugs at temperatures between $40-43^{\circ} \mathrm{C}$, up to $3 \mathrm{~mm}$ into the peritoneal tissue to target micrometastic lesions of the peritoneal surfaces [9]. Delivery of certain chemotherapeutic agents, including doxorubicin, melphalan, mitomycin $\mathrm{C}$ (MMC), mitoxantrone, gemcitabine, etoposide, and the platinum-based agents carboplatin, cisplatin and oxaliplatin can be potentiated with hyperthermia. Although survival rates have dramatically improved using HIPEC in combination with surgical resection, the drawbacks to the procedure include long operative times and large quantities of drug perfusate (2L) [9].

Hyperthermia has been shown to influence apoptosis by a well-understood signaling cascade. Upon ligation of a death receptor by its naturally occurring ligand cells propagate through the apoptotic cascade (Fig. 2). Cells undergoing apoptosis sustain profound changes, including the development of blebs on the cell membrane, volume contraction, nuclear condensation (pyknosis), and activation of an endonuclease that cleaves the DNA. Some of the genes associated with apoptosis include bcl-2, p53, Bax, Bak, myc, and abl. In addition, there are many growth factors that influence cell death in both normal and neoplastic cells. Since apoptosis is genetically controlled, defects in the control pathway or overexpression of proteins that suppress apoptosis may contribute to development of cancer. Cancer cells that are resistant to conventional therapies often over-express antiapoptotic proteins such as bcl-2. Manipulating proapoptotic proteins such as Bax or antiapoptotic proteins such as Bcl-2 are being explored as optional anti-cancer treatments. Hyperthermia in combination with other therapies results in the induction of apoptosis via activation of caspase 8 (Type 1) or disruption of mitochondrial function (Type 2) [10,11]. For example, Tu et al. showed that caspase 2 and RAIDD are key elements in hyperthermia-induced apoptosis and Pagliari et al. showed that hyperthermia activates Bax and Bak, to induce type 2 apoptosis via mitochondrial pathways [12].

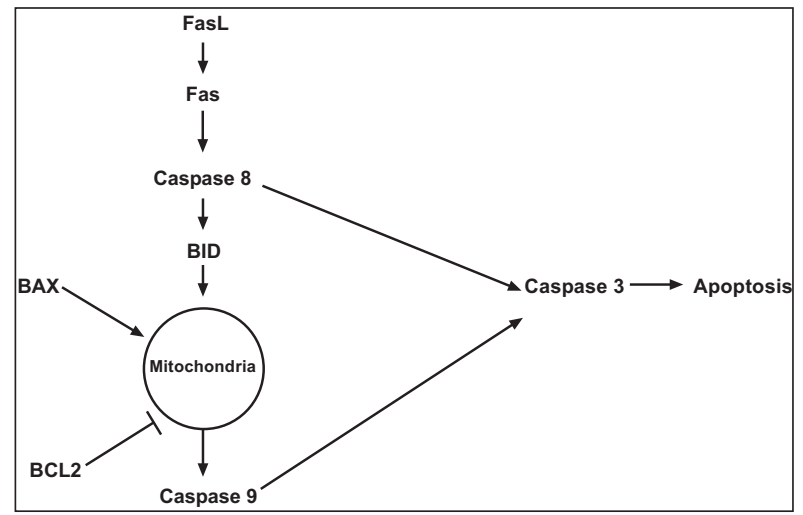

Fig. (2). Apoptotic cascade leading to cell death.

Hyperthermic ranges used with drugs are critical for maximizing treatment effectiveness; appropriate ranges are between $40-43^{\circ} \mathrm{C}[4,9]$. Temperatures above $45^{\circ} \mathrm{C}$ result in the coagulation of proteins and irreversible cell damage [6].

Heat shock proteins (HSP) are important protective mechanisms that inhibit cell apoptosis pathways. Heat shock proteins (HSP) are induced at hyperthermic temperatures, especially above $45^{\circ} \mathrm{C}$ and HSPs can modify the induction of cell death [6]. Elevated levels of HSP are found when cells are subjected to elevated temperatures, drugs, UV irradiation, glucose deprivation, cytoskeletal perturbation, hypoxia or other stress [13-21]. Upregulation of HSPs protects cells and makes them more resistant to chemotherapy, hyperthermia and radiation treatments [6]. HSP's are classified according to their molecular weights and help mediate cell 
damage by initiating mechanisms for repair of misfolded proteins that have been damaged or they can inhibit caspase activation and thus prevent apoptosis [18, 20-22]. HSPs 70, 90, and 27 can also promote cell survival mechanisms [13]. For example, HSP70 can suppress caspase- 8 activation which in turn can suppress apoptosis [13]. There is also a possible synergistic effect dietary flavonoids can exert on heat shock proteins leading to a decrease in resistance to chemotherapy of cancer cells. Flavonoids are pigments found in many brightly-colored plants. The common dietary flavonoid, quercetin has been shown to down-regulate the expression of heat shock proteins, HSP90, HSP70, and HSP27. The benefits have been shown in multiple types of cancer including head and neck, colorectal, cervical and prostate [23-27]. In addition, the pre-incubation of cervical cancer cells with quercetin prior to treatment with cisplatin activates caspase-3 as well as inhibits HSP72 [24]. There may be a unique opportunity to further combine flavonoids with hyperthermic chemoperfusion, either with or without nanoparticles, for the treatment of cancer to aid in overcoming drug or heat resistance by tumor cells.

\section{Clinical Application of Hyperthermia- Intraperitoneal Hyperthermic Chemotherapy}

Dissemination of tumor micrometastasis often occurs with intra-abdominal malignancies and is usually restricted to the parietal and visceral peritoneum. Without treatment peritoneal malignancies can progress to bowel obstruction and/or to an overwhelming number of malignant ascites, as shown in Fig. (3). The mechanism of intraperitoneal tumor spread seems to follow three patterns. The first pattern is that of direct extension, the second involves distribution of tumor cells via peritoneal fluid, and the third is by surgical manipulation/trauma. Exfoliated tumor cells are thought to become entrapped in avascular scar tissue- and hence can become resistant to intravenous chemotherapy [28-30]. Surgical cytoreduction alone or combined with radiation or systemic

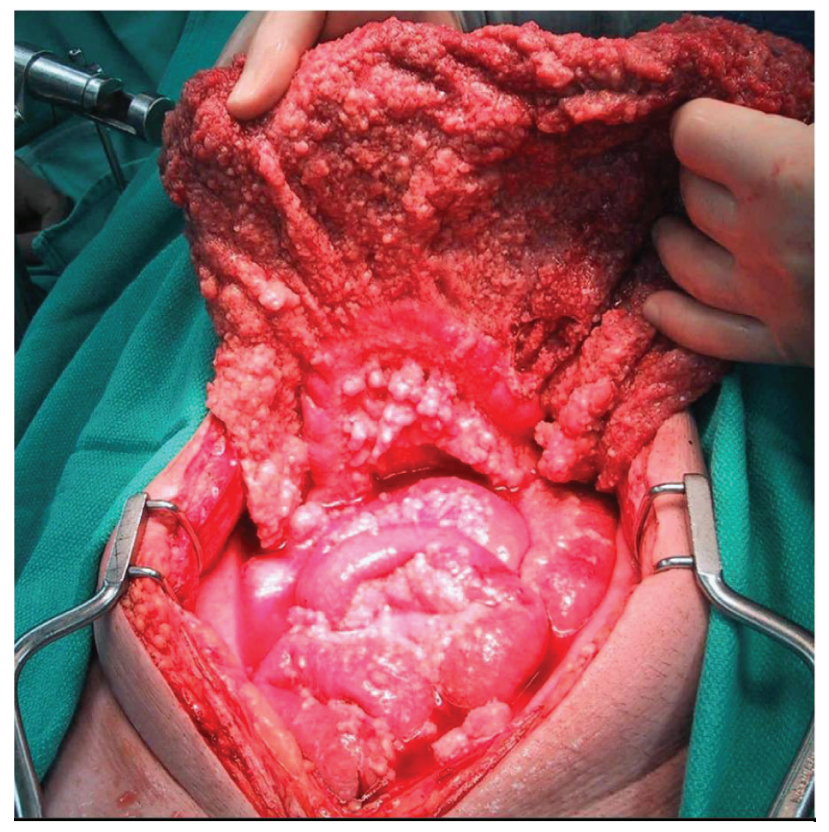

Fig. (3). Massive peritoneal surface dissemination from a gastrointestinal primary tumor. chemotherapy are not often efficient treatments for peritoneal surface disease. Our group has added HIPEC to tumor debulking in an effort to improve survival in this group of patients. A schematic of the perfusion set-up is shown in Fig. (4). The main course of treatment is aggressive surgical cytoreduction as even the most ambitious perfusion strategies penetrate but a few millimeters. Removal of bulk disease is imperative so that only small tumor volumes and micrometastasis remain thus allowing adequate perfusion treatment.

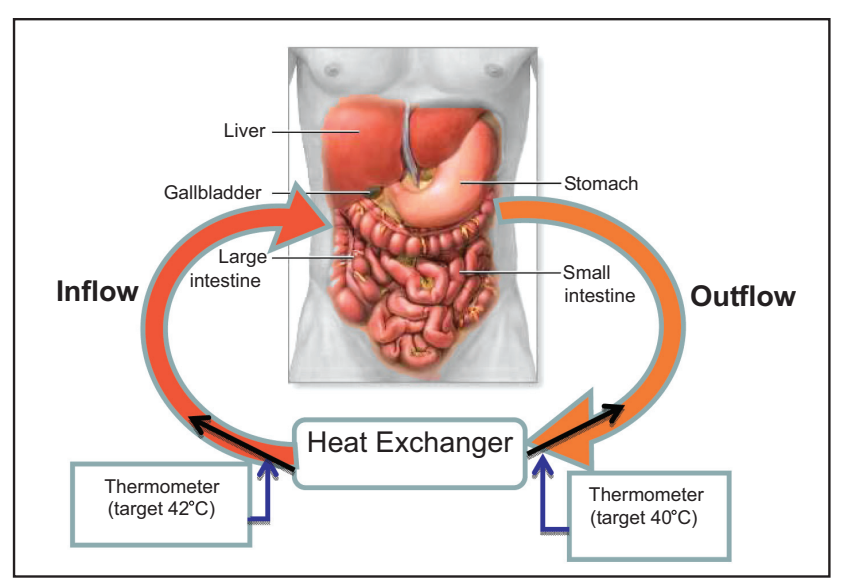

Fig. (4). Schematic clinically used of HIPEC circuit diagram.

Cyto-reductive surgery and HIPEC for patients with colorectal cancer and its peritoneal disseminations results in median survival time of 13-60 months, compared to surgical resection and reduction alone ( 0.7 to 6 months) or systemic chemotherapy (24 months) [31]. Long term survival for HIPEC-treated patients with peritoneal surface malignancy is about $25 \%$ with a median survival time of 22.3 months compared to only 12.6 months for surgical resection and systemic chemotherapy [32]. A peritoneal-plasma partition exists which limits the entry of systemic chemotherapy into the peritoneum. Clinical data has shown that clearance is inversely proportional to the square root of its molecular weight of the delivered agent [33-35]. Therefore, drugs with high molecular weights have optimal pharmacokinetic profiles for intraperitoneal application. The pharmacokinetic advantage of intraperitoneal perfusion can be expressed by area under the curve (AUC) ratios of peritoneal fluid to plasma as shown in Table 1 [36-42]. In our own phase I trial of oxaliplatin for HIPEC, we saw a significant pharmacokinetic advantage to intraperitoneal delivery of oxaliplatin relative to systemic delivery, as shown in Table $\mathbf{2}$. Indications for combined use of cytoreductive surgery and HIPEC include presentation of malignant disease confined to the parietal peritoneum that is completely resectable or can be significantly reduced. In addition, patients must have normal organ function defined as serum creatinine $<2 \mathrm{mg} / \mathrm{dL}$, alkaline phosphatase and serum aspartate transaminase or alanine transaminase $<3$ times the upper limits, white blood cell count $>4000 / \mathrm{mm}^{3}$, and platelet count $>100,000 / \mathrm{mm}^{3}$ [4]. Lastly, patients must be medically fit enough to undergo the rigors of cytoreductive surgery and HIPEC which can range from 4-18 hours and averages 9 hours [4]. Peritoneal lesions are best discovered preoperatively using computer tomogra- 
phy (CT) or magnetic resonance imaging (MRI), with MRI being more sensitive for detecting low-volume disease with $84-100 \%$ confidence [4].

Table 1. Molecular Weights and Peritoneal to Plasma Area Under the Curve (AUC) for Drugs Commonly Used for Intraperitoneal Chemotherapy. Reproduced from $[50]$

\begin{tabular}{|c|c|c|}
\hline Drug & $\begin{array}{c}\text { Molecular Weight } \\
\text { (Daltons) }\end{array}$ & $\begin{array}{c}\text { AUC ratios of peritoneal } \\
\text { fluid to plasma }\end{array}$ \\
\hline \hline MMC & 334 & $75: 1[38]$. \\
\hline 5 FU & 130 & $300: 1[39]$. \\
\hline FUDR & 246 & $2000: 1[40]$. \\
\hline Doxorubicin & 544 & $975: 1[37]$. \\
\hline Cisplatin & 300 & $20: 1[36]$. \\
\hline Paclitaxel & 808 & $1000: 1[41]$. \\
\hline Oxaliplatin & 397 & $14: 1[42]$. \\
\hline
\end{tabular}

Table 2. Amount of Oxaliplatin in Fluid and Tissues Following Standard HIPEC Treatment. Reproduced from [50]

\begin{tabular}{|c|c|c|c|}
\hline & $\mathbf{2 0 0} \mathbf{~ m g / m 2}$ & $\mathbf{2 5 0} \mathbf{~ m g} / \mathbf{m} \mathbf{2}$ & $\mathbf{p}$ \\
\hline \hline Peritoneal Fluid (mg/L) & $14.2 \pm 4.2$ & $15.9 \pm 2.9$ & 0.47 \\
\hline Plasma (mg/L) & $0.7 \pm 0.3$ & $0.8 \pm 0.3$ & 0.88 \\
\hline Normal tissue (mg/L) & $17.7 \pm 10.8$ & $26.3 \pm 14.7$ & 0.35 \\
\hline Tumor (mg/L) & $15.9 \pm 12.0$ & $20.3 \pm 9.7$ & 0.48 \\
\hline
\end{tabular}

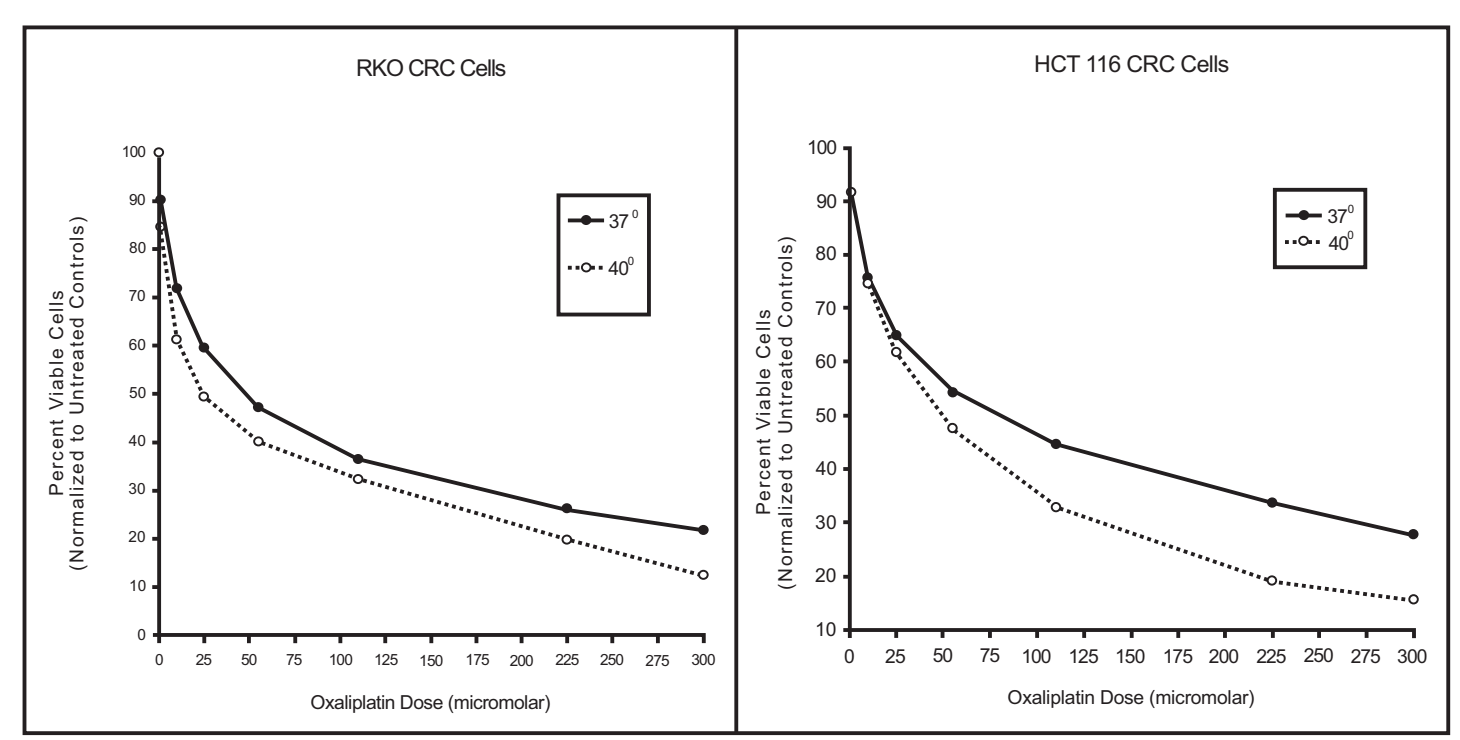

Fig. (5). Response of RKO and HCT 116 colorectal cancer cells to combined treatment of hyperthermia and oxaliplatin. Reproduced from [55].
HIPEC not only exposes tumor cells to chemotherapy, but it may also overcome the drug resistance associated with systemic delivery. Previous studies have shown that mild hyperthermia enhances the anti-tumor effects of mitomycin $\mathrm{C}$, and cisplatin. Our own research further demonstrates that hyperthermia sensitizes colorectal cancer cell lines to the cytopathic affects of oxaliplatin [43]. HCT 116 colorectal cancer cells at $37^{\circ} \mathrm{C}$ had a half maximal inhibitory concentration $\left(\mathrm{IC}_{50}\right)$ of $144 \mu \mathrm{M}$ of oxaliplatin. There was a dramatic hyperthermia-mediated sensitization to oxaliplatin with an $\mathrm{IC}_{50}$ value of $57 \mu \mathrm{M}$ at $40^{\circ} \mathrm{C}$. An alternate cell line, $\mathrm{RKO}$ colorectal cancer cells, were also sensitized by hyperthermia with a reduction in the oxaliplatin $\mathrm{IC}_{50}$ values from $89 \mu \mathrm{M}$ at $37^{\circ} \mathrm{C}$ to $59 \mu \mathrm{M}$ at $40^{\circ} \mathrm{C}$. (See Fig. 5) Hyperthermia increased the cellular uptake of oxaliplatin in both HCT 116 and RKO cell lines as determined by atomic absorption analysis. After a 2 hour incubation in $300 \mu \mathrm{M}$ of oxaliplatin at $37^{\circ} \mathrm{C}$, the intracellular concentration of platinum in HCT 116 cells was $837 \pm 16.2 \mathrm{ppb}$ while that of RKO cells was $345.5 \pm 16$ parts per billion (ppb). Hyperthermia at $42^{\circ} \mathrm{C}$ increased the intracellular platinum concentration in HCT116 to $1016.4 \pm 18.3$ ppb while hyperthermia at $40^{\circ} \mathrm{C}$ increased the intracellular platinum concentration in RKO cells to $511.2 \pm 23.2 \mathrm{ppb}$. This set of data clearly demonstrates the beneficial effects of hyperthermic chemotherapy.

\section{NANOPARTICLES AND HYPERTHERMIA}

The new era of hyperthermic medical treatments not only includes the use of nanoparticles for delivery of hyperthermia for ablation of tissues, but it also includes evaluations of effective delivery of chemotherapeutic agents to cancer cells. Carbon nanotubes and nanohorns, gold nanoshells, solid gold nanoparticles and iron oxide nanoparticles are all capable of producing hyperthermia. The premise for generation of heat using incident radiation like infrared light is plasmon resonance of the nanoparticles. Small dimension nanoparticles have begun to be exploited in medicine to increase circulation times and tumor targeting. Nano-sized particles avoid immune system clearance and have the potential to localize readily in tumor architectures via tumor vasculature. 
The vascular supply of developing tumors has larger gaps between endothelial cells than fully developed vasculature of normal organ tissue, which makes tumors susceptible to nanoparticle infiltration. The small size permits nanoparticles to be transported through organs perhaps more easily than larger molecule drugs. The fundamental concept of nanoparticles' enhanced permeability and retention (EPR) is an important characteristic that can be exploited, for applications in oncology as well as in other areas of drug delivery [44-47].

\section{Properties of Nanoparticles Useful for Hyperthermia}

Prior to the discovery of the fullerene in 1986 by Smalley, Curl and Kroto graphite and diamond were the known carbon allotropes [48]. Although pyrolitic, or glassy carbon has been used in medical applications for coating implanted devices, the use of carbon for drug delivery has only in the past decade begun to be explored $[49,50]$. Fullerenes are classified in two forms: the more spherically shaped molecules are called fullerenes or bucky balls $\left(\mathrm{C}_{60}\right)$ and the more tubular shaped molecules called carbon nanotubes. Some of the original work on fullerenes in medicine was the exploration of $\mathrm{C}_{60}$ for inducing free radical species upon stimulation with light. This principle has evolved into the use of carbon nanotubes for this purpose. However, the majority of literature employs $\mathrm{C}_{60}$ and nanotubes for drug delivery and nanotubes for hyperthermia.

Carbon nanotubes with one sidewall are referred to as single-walled tubes, whereas tubes with two or more sidewalls are referred to as double-walled, or multi-walled nanotubes (SWNT, DWNT, or MWNT). Single wall nanotubes (SWNT) are about $1 \mathrm{~nm}$ in diameter, and hundreds of nanometers long, whereas multi-walled nanotubes (MWNT) have diameters up to about $20-30 \mathrm{~nm}$ and lengths into the multiple micron range. MWNT can also have diameters up to hundreds of nanometers, if grown through templating methods. This can often be exploited to aid in filling of the nanotubes with therapeutic agents for loco-regional delivery at a localized site. The small size of nanotubes confines the electrons to the length of the nanotube rather than around the circumference; this can alter the quantum mechanically al- lowed modes of the system [51]. When a metal catalyst is used for growth, the ends of the nanotubes contain a metal seed and are often capped; this can further add mass to the tubes and influence thermal generation when the nanotube is stimulated. Nanotubes doped with atoms such as nitrogen and boron along the lattice sidewalls are being explored for medicinal applications since they may have reduced toxicity compared to undoped nanotubes [52-55]. Small- scale dimension affords the carbon nanotubes with special properties; Carbon Nanotubes not only have high electrical conductivity but they also high thermal conductivity, heat capacity, excellent mechanical strength along the tube axis, and are resilient to mechanical distortion [51,56-60]. The generation of hyperthermia using nanotubes can depend upon how the nanotubes are processed as defects and the length of the tubes can influence their interactions with incident radiation [61]. Cleaning by oxidative treatments can remove the caps at the ends of the tubes so they could be filled with agents, but this process also shortens the tubes depending upon the time and strength of the oxidative treatment [62-66].

Depending on how the nanotube sidewall is rolled (chirality) nanotubes can be classified as metallic or semiconducting which influences their electrical and thermal properties [51]. Fig. (6a) shows the two dimensional graphite lattice and the chiral vector, $\mathrm{C}=\mathrm{na}_{1}+\mathrm{ma}_{2}$, which describes how the nanotube rolls. Values in parenthesis are integral values, denoted $(n, m)$, and are the chiral coefficients that can be used to describe the electronic structure of the nanotube. For example, $m=n$, armchair; $m, n=0$, zig-zag; $m \neq n$, chiral (Fig. 6b), and whether the folded points will produce a metallic or semi-conducting nanotube [67-69].

Transitions between the first and second van Hove singularities (electronic transitions) permit carbon nanotubes to absorb electromagnetic radiation, with peaks in absorption in the infrared range, as shown in the absorption spectra in Fig. (7) $[61,70-73]$. Nanotubes generate heat by absorbing incident light which induces phonon and plasmon resonances along the tube length [74-76]. Both metallic and semiconducting nanotubes are able to absorb infrared radiation strongly and in turn generate heat due to phonon resonance [74]. Plasmon and phonon resonances are associated with

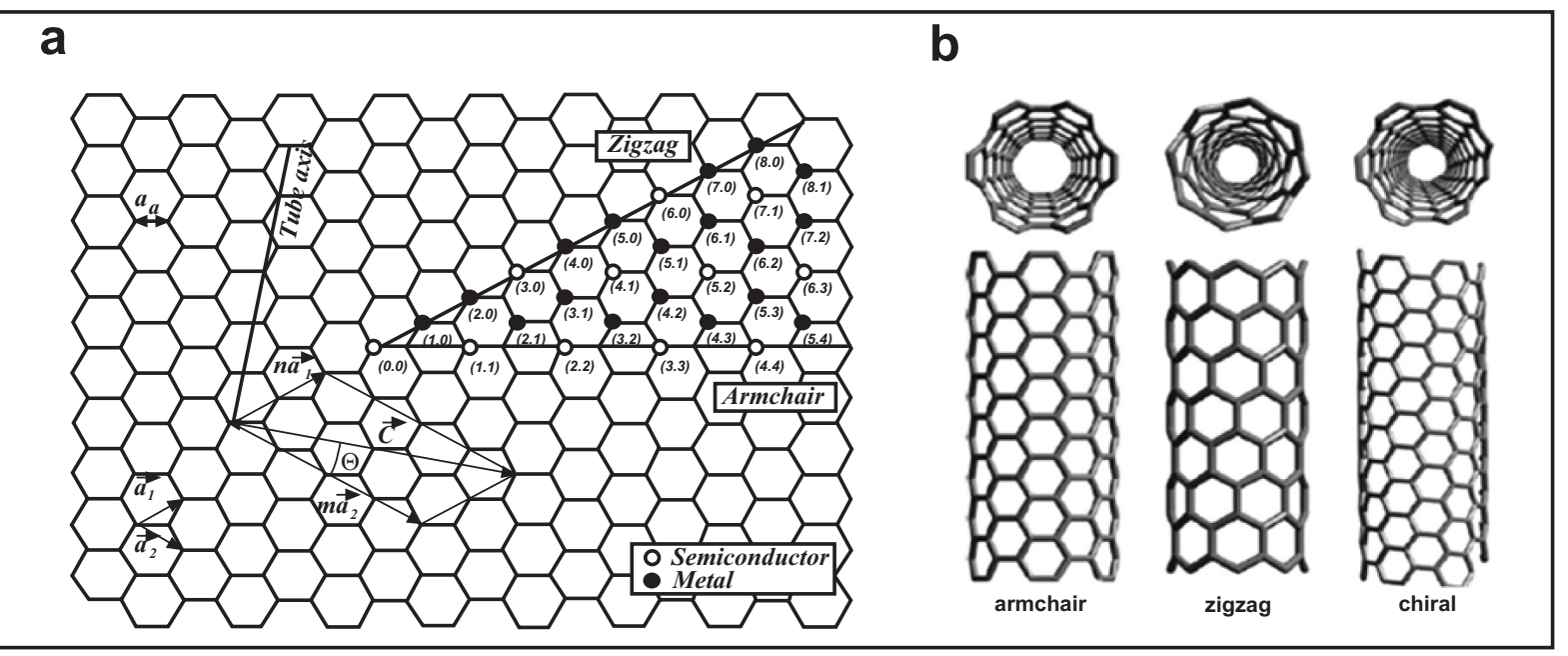

Fig. (6). Chirality vector and folding scheme for semiconducting and metallic nanotube (a). Zig-zag, armchair, and chiral nanotubes by rolling-up of the graphite lattice (b). Reproduced from [78]. 
nanotube geometry and can be observed in peaks in the absorption spectra from the nanotubes. Absorption is dependent more on the length of the nanotube than the diameter; therefore the length of the nanotubes can be modified by oxidative treatments to efficiently couple to a specific frequency of light [74]. Based on antenna theory, the length of the nanotube predicts the wavelength the nanotube will most specifically absorb. Nanotube absorption will be most efficient when the nanotube length is a multiple of half the wavelength of the incident light [77-80]. The spectral region where water, and hemoglobin exhibit absorption minima is between $700-900 \mathrm{~nm}$ and near $1100 \mathrm{~nm}$ (see Fig. 8) [81,82]. Cosmetic procedures such as dermal resurfacing often use $1064 \mathrm{~nm}$ (Nd:YAG) lasers. For the clinically relevant lasers operating at $800 \mathrm{~nm}$ and $1064 \mathrm{~nm}$, maximum absorption should occur for nanotubes longer than $400 \mathrm{~nm}$ or $532 \mathrm{~nm}$. Furthermore, MWNT might be more efficient than SWNT due to their additional mass and interaction of nanotube sidewall resonance, which aid in heat transfer from nanotubes $[83,84]$.

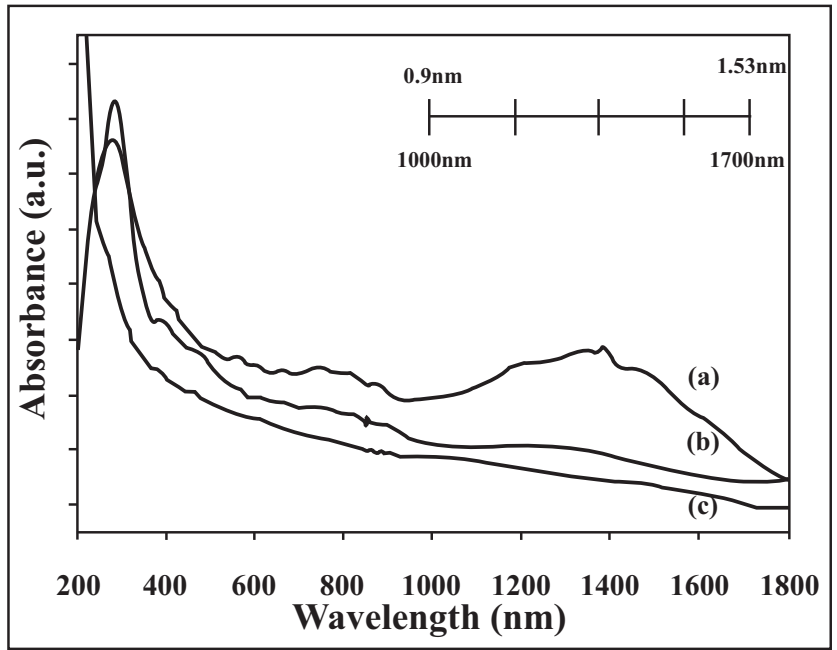

Fig. (7). Carbon nanotubes have an absorption peak between 1000 and $1500 \mathrm{~nm}$ as defined by line a in this figure. A decrease in absorption is seen in lines $b$ and $c$ due to wrapping of polysaccharides around the tubes for water solubilization. Reproduced from [84].

Tight bundles of nanotubes termed 'nanobombs' have been shown to generate powerful microscopic explosions when excited by infrared radiation $[85,86]$. The 'bomb' effect occurs due to the rapid heating of the nanotube bundles, and the air trapped within the bundle. The air heats rapidly and expands, causing the burst of heat and cavitation. The miniscule explosions may be beneficial for eradication of tumor cells, but the effect can also result in the regional spread of cells from the primary tumor mass, leading to in transit metastasis. Although it is unknown how much heat is generated at the surface of nanotubes, previous studies have used both SWNT and MWNT to rapidly heat above $45^{\circ} \mathrm{C}$, leading to thermal ablation and cell death, as shown in Fig. (9) $[62,63]$. As shown in Fig. (10), both SWNT and MWNT generate significant increases in the temperature of a bulk solution when stimulated by $1064 \mathrm{~nm}$ light. However, MWNT are more efficient generators of hyperthermia as lower concentrations of MWNT generate significantly more heat than SWNT.

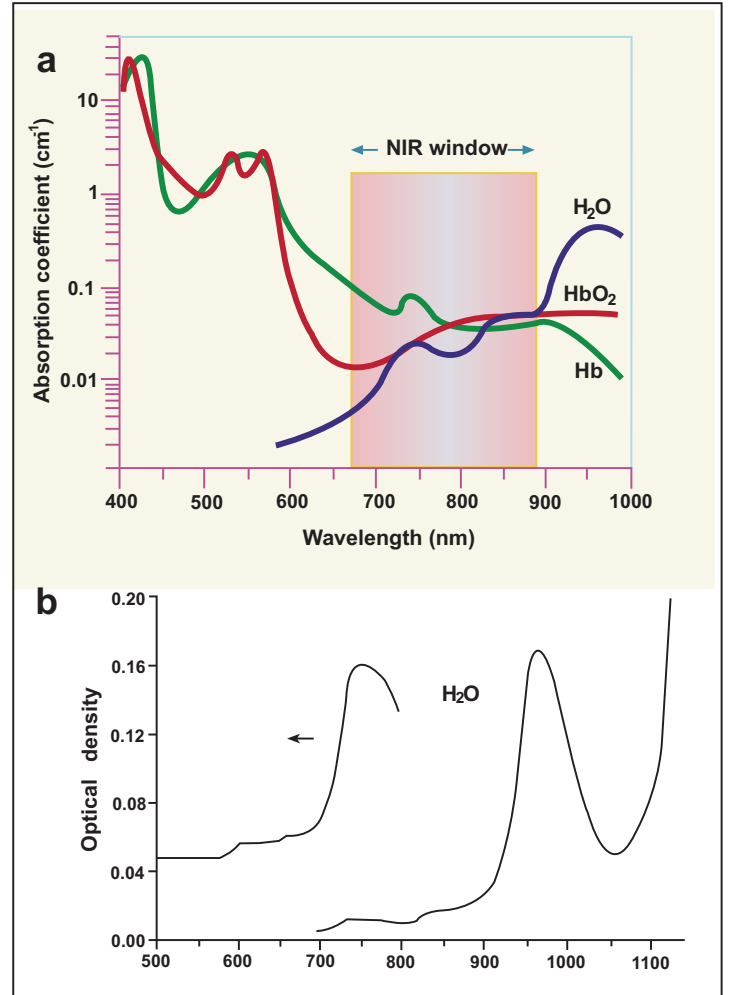

Fig. (8). The best regions for nanotube absorption lie where water and hemoglobin have absorption minima: between 700 and $900 \mathrm{~nm}$ (a) and around 1050nm (b). Reproduced from [92] and [93].

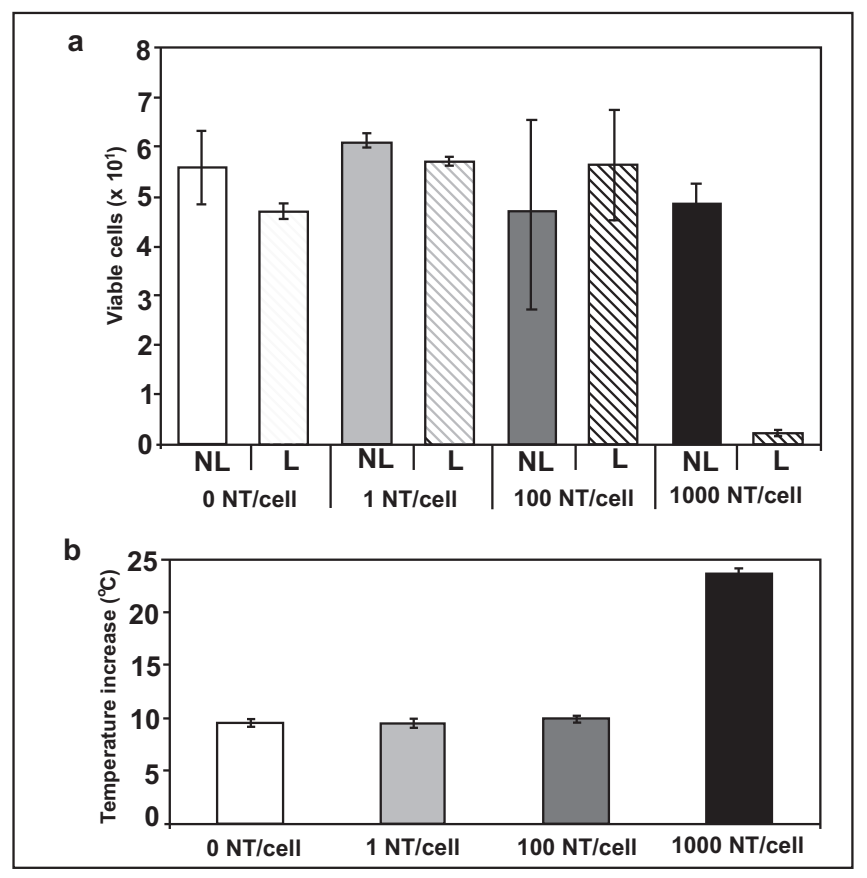

Fig. (9). MWNT, 1100nm in length are efficient generators of heat in a bulk solution leading to cell death. Within sixty seconds of exposure temperature increases of almost $25^{\circ} \mathrm{C}$ over the baseline, or up to almost $60^{\circ} \mathrm{C}$ can be achieved. Kidney cancer cells exposed to such a high temperature undergo irreversible cell damage leading to death. The number of nanotubes needed for efficient cell killing was found to be 1000 nanotubes per cell with exposure to $1064 \mathrm{~nm}$ light (L). With no light exposure (NL) the amount of cells killed was statistically the same as control cells without nanotubes or light exposure. Reproduced from [73]. 


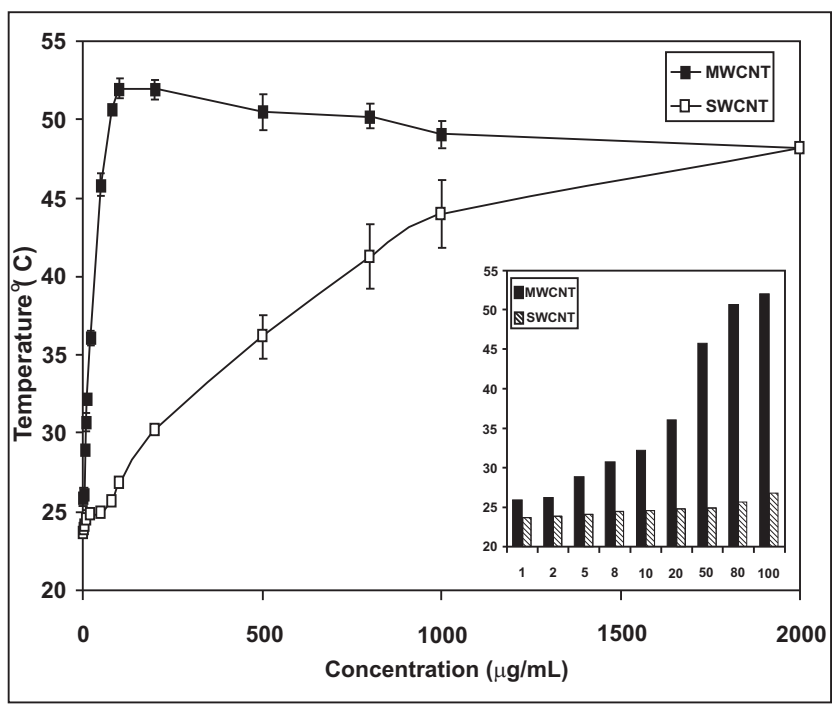

Fig. (10). Well- dispersed MWNT generate a greater temperature than well-dispersed SWNT for all concentrations up to $2 \mathrm{mg} / \mathrm{ml}$. Reproduced from [100].

\section{Benefits and Limitations}

Many cancer types express specific markers on their cell surface that can be used for targeting nanoparticles to cancer cells. For example, many cancers, express more folic acid receptors on their surfaces than normal cells do. So, nanotubes with functionalized sidewalls that display folic acid will bind to the folic acid receptors on cancer cell membranes. See Fig. (11) [63]. As a future challenge, the nanotubes with functional groups attached to their sidewalls can lose their functional molecules due breakage of the bonds during hyperthermia. This is expected to be more problematic for higher ablation temperatures and less so for mild hyperthermia that should be used to enhance drug delivery.

Although infrared radiation has the potential to excite nanotubes and hence generate heat, it can only pass through less than $2 \mathrm{~cm}$ of tissue for $1064 \mathrm{~nm}$ light. However, for dermal applications or malignancies that can be accessed using endoscopy or during open surgical technique, light stimulation of nanotubes is very promising.

An alternative to inducing hyperthermia via infrared intimidation of carbon nanotubes is the use of radiofrequency. The treatment of radiofrequency ablation is commonly employed for kidney, bone, liver, and pancreatic cancers. Generation of hyperthermia using SWNT coupled with radiofrequency was attributed to the electrical resistance in nanotubes with high aspect ratios [87]. A recent report used SWNT in an applied radiofrequency field for thermal ablation of hepatic and pancreatic tumors. SWNT generated hyperthermic temperatures rapidly via stimulation with radiofrequency at $13 \mathrm{MHz}, 600 \mathrm{~W}$ for two minutes. The authors noted substantial cell death in the in vitro study and significant reduction in tumor volumes in the in vivo studies [87]. Results of the study further indicate the importance of the length of nanotubes has upon interaction with the incident electromagnetic field to generate heat. Hyperthermia generated using SWNT with RF is shown in Fig. (12). However, the radio frequency experiments in the literature used a high quantity of SWNT, $500 \mathrm{mg} / \mathrm{ml}$, in in vivo experiments, whereas other authors, Torti et al., Levi-Polyachenko et al., and Burke et al., used 100mg/ml MWNT, and Kam et al., used $5 \mathrm{mg} / \mathrm{ml}$ folic acid ligand targeted SWNT to achieve sufficient heating $[62,63,88,89]$. Thus, although the use of radiofrequency to generate hyperthermia from SWNT is possible, for clinical use it would be optimal to reduce the quantity of nanotubes towards the lower doses used with other nanotube hyperthermia treatments.

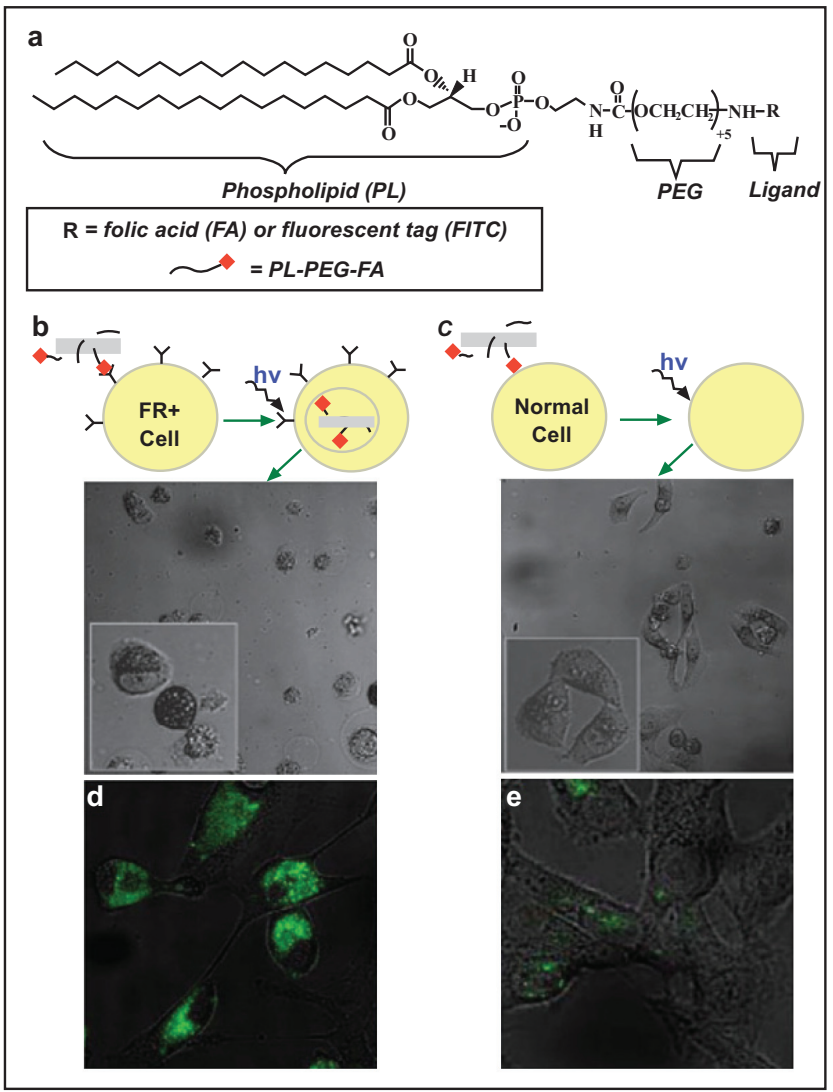

Fig. (11). Folic acid can be conjugated onto nanotubes fluorescently labeled nanotubes to target cells expressing folic acid receptors $(\mathbf{a}, \mathbf{b}, \mathbf{c})$. Nanotubes conjugated with folic acid display a fluorescent signature indicating that nanotubes are internalized by cells expressing folic acid receptors (d). Without the folic acid conjugate, there is very little distribution of nanotubes within the cells as attributed by the lack of fluorescent signature in (e). Reproduced from [74].

Although SWNT and MWNT are potentially very useful for inducing hyperthermia there may be some toxicity issues that need to be overcome prior to their clinical use. High aspect ratio nanoparticles, such as nanotubes, may be difficult for clearance by the immune system. The biopersistence of nanotubes will most likely depend upon the length. Provided that the appropriate aspect ratio for macrophage and neutrophil phagocytosis is chosen, this toxicity could be avoided. Biopersistence can also lead to fibrosis in the areas of nanotube deposition. This is an unknown avenue that needs to be explored, since there is currently no information on clearance of nanotubes prior to localized thermal treatments of tumors. A final point that must be addressed is aggregation of the nanotubes in vivo. Although nanotubes can be readily functionalized to minimize aggregation, once hyperthermia is induced, the nanotubes can lose their func- 
tional molecules due to bond breakage from the heat. Therefore, the tubes could aggregate and potentially cause unwanted micro-thromboses and a failure of immune system clearance.

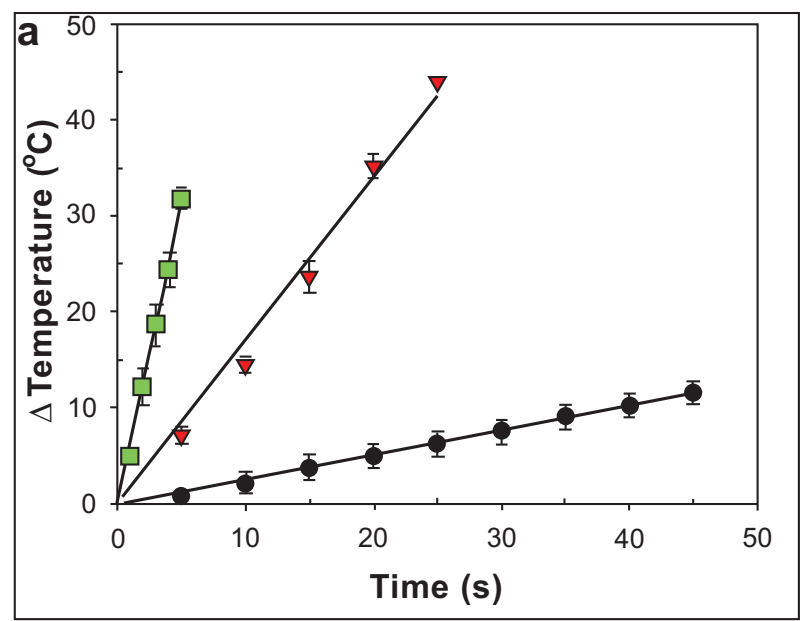

Fig. (12). Hyperthermia generated by SWNT in aqueous suspension stimulated with radiofrequency $(600 \mathrm{~W})$. Black circles indicate no SWNT, red triangles indicate SWNT at a concentration of $50 \mathrm{mg} / \mathrm{L}$, and green squares indicate SWNT at a concentration of $250 \mathrm{mg} / \mathrm{L}$. [98].

Interestingly the amount of energy required to induce hyperthermia is dependent on the location of the nanoparticle in the cell. Recent work by Tong et al. found this. Ten times less laser energy is needed to cause hyperthermia when the nanoparticles reside in the cell membrane compared to within the cytoplasm [90]. Their results indicate that hyperthermia using nanoparticles might be most effective for modifying cell membranes to facilitate drug transport.

\section{Potential for Clinical Applications}

One of the most important uses for nanotube induced hyperthermia is to facilitate heat generation near cell membranes to enhance membrane permeability and enhance drug uptake. This has been explored using a comparison of colorectal cancer cells treated with standard HIPEC therapy or nanotube induced hyperthermia using oxaliplatin. As shown by Levi-Polyachenko et al., Figs. (13 and 14), MWNT can be used to generate rapid hyperthermia to $42^{\circ} \mathrm{C}$ and can increase cellular uptake of oxaliplatin by colorectal cancer cells leading to a reduction in cell population similar to the standard two hour hyperthermia treatment at $42^{\circ} \mathrm{C}$ [89]. Laser stimulation without MWNT had similar results to control cells treated at $37^{\circ} \mathrm{C}$.

In addition to delivering hyperthermia with chemotherapeutic agents, nanoparticles are routinely explored as drug delivery vehicles of chemotherapeutic agents directly to cells and tissues without hyperthermia. For example, Liu et al., delivered paclitaxel to breast cancer tumors in mice by attaching it to SWNT [91]. The results indicated a ten fold higher increase of the drug labeled SWNT into the tumors compared to delivery of the drug, alone due to longer in vivo circulation times and higher water solubility of the paclitaxel SWNT complex [92]. This resulted in a significant decrease in tumor volumes as shown in Fig. (15). In an additional a

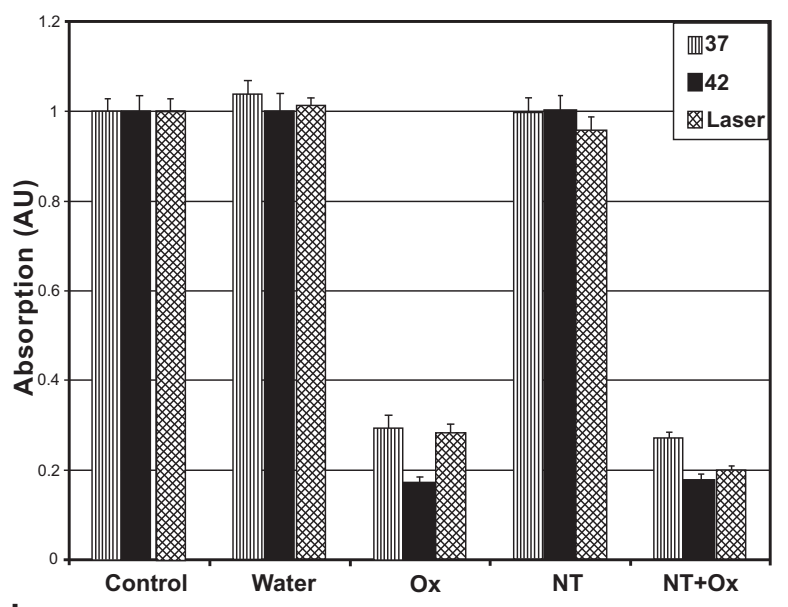

b

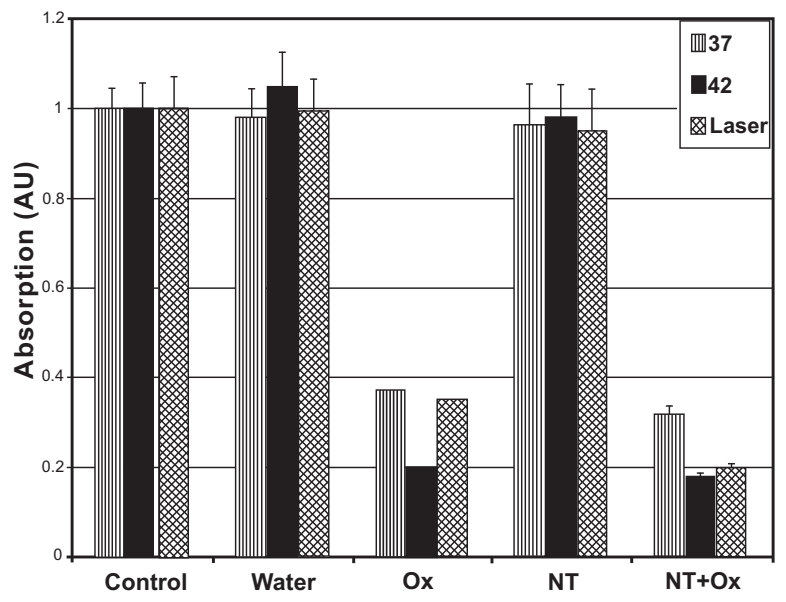

Fig. (13). HCT 116 (a) and RKO (b) colorectal cancer cell lines response to nanotubes (NT), laser application and oxaliplatin (Ox). Reproduced from [99].

study Zhang et al., used the polymers alginate or chitosan to attach doxorubicin to SWNT for release at low $\mathrm{pH}$ such as that which occurs in lysosomes [93]. An additional functional group using folic acid aided in targeting the SWNT to the folic acid receptor expressing HeLa cervical cancer cells. Although there is some difficulty with complete drug release (about 50\% using chitosan and approximately 30\% using alginate or no polymer), this represents an alternate potential mechanism for delivery of chemotherapeutic agents using nanoparticles. DNA can also be attached and delivered using SWNT. Subsequent stimulation with infrared light can result in the release of the DNA from the tube. Nanoparticles of gold and carbon can also be imaged in vivo by labeling them with radioisotopes for positron emission tomography, magnetic materials for magnetic resonance imaging or imaging ultrasound due to the difference between density of nanoparticles compared to the density of the surrounding tissues.

Magnetic nanoparticles such as iron oxide are routinely employed to generate hyperthermia in vivo. For example, Purushotham et al. used iron oxide nanoparticles to generate hyperthermia, as shown in Fig. (16). A novel aspect of their 
a

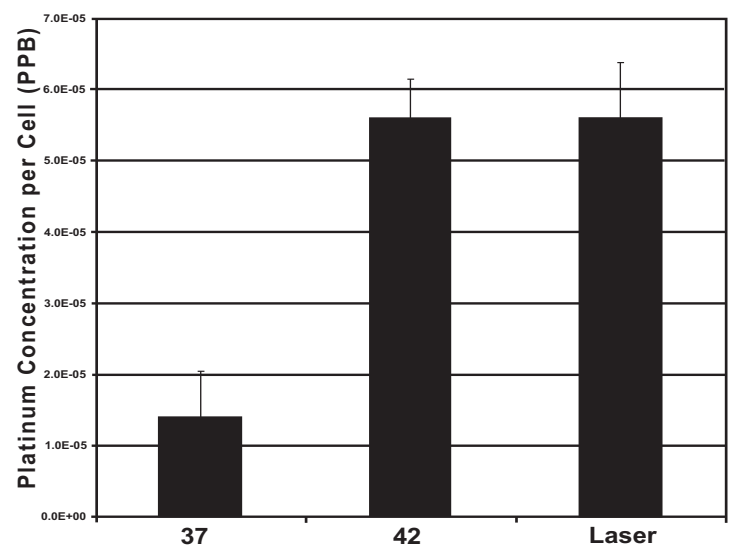

b

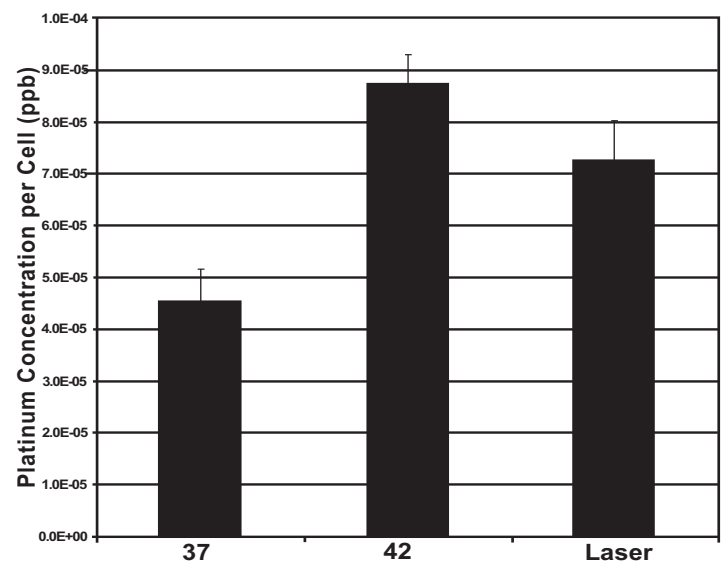

Fig. (14). The amount of platinum per RKO (a) or HCT 116 (b) colorectal cancer cell treated at 37,42 , or $42^{\circ} \mathrm{C}$ rapidly by infrared laser stimulation of nanotubes. Reproduced from [99].

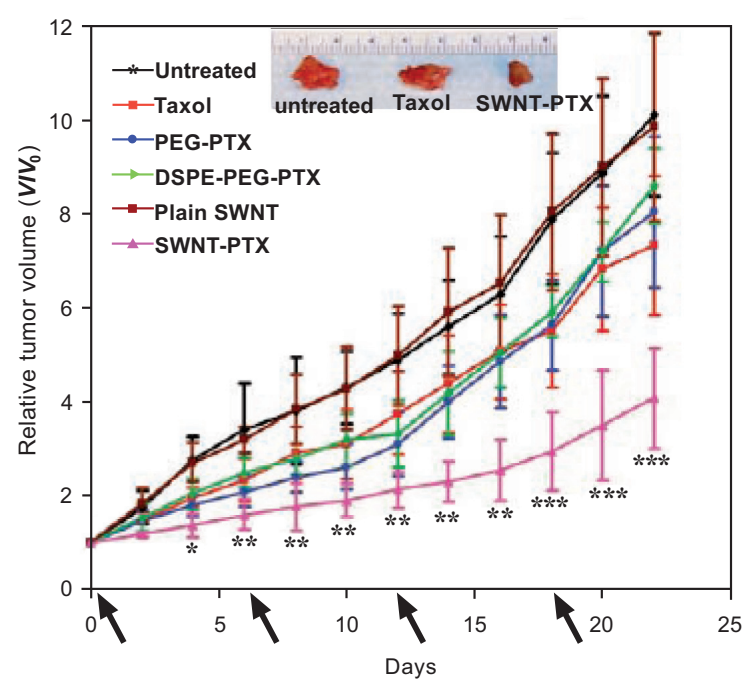

Fig. (15). Growth of breast cancer tumors in mice treated with $0.5 \mathrm{mg} / \mathrm{kg}$ SWNT-paclitaxel complex compared to SWNT, Taxol, and polyethylene glycol functionalized paclitaxel. The insert shows the decrease of tumor volumes for the various treatments. Reproduced from [101].

work was that they functionalized the magnetic nanoparticles in order to generate hyperthermia and subsequent release of the chemotherapeutic agent, doxorubicin from a polymer coating on the nanoparticles [94].

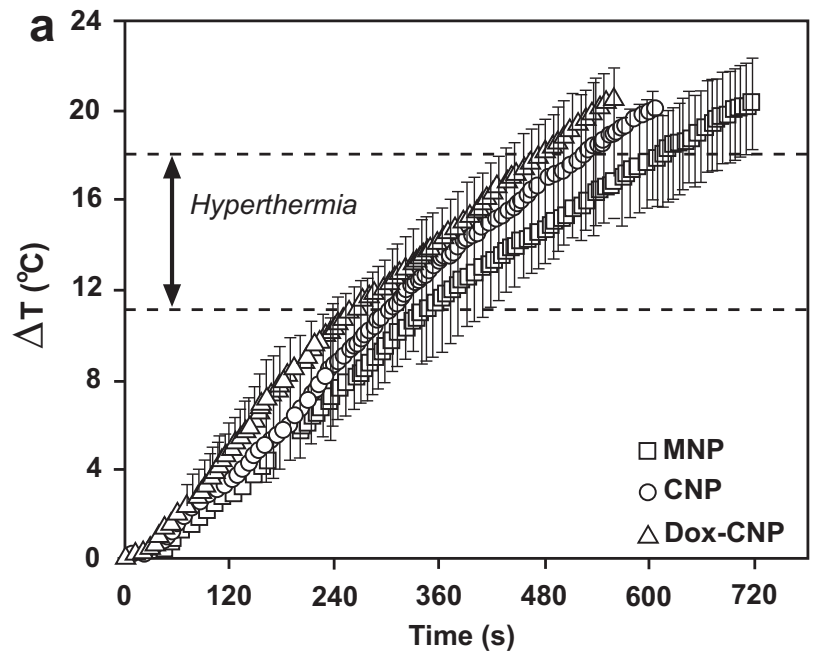

Fig. (16). Heating curves of $\mathrm{Fe}_{3} \mathrm{O}_{4}$ nanoparticles in an alternating magnetic field with field strength of $4 \mathrm{kA} / \mathrm{m}$ at a frequency of $375 \mathrm{kHz}$ and a concentration of $2 \mathrm{mg} / \mathrm{ml}$. MNP is magnetic nanoparticle, CNP is a MNP coated with a polymer shells, and Dox-CNP is a CNP with doxorubicin attached to the polymer. Reproduced from [103].

The mobility of electrons is dependent upon the size and shape of a given nanoparticle. For example, noble metal nanoparticles can essentially trap incident photons which, in turn, set up surface plasmon resonance (SPR) that can be tuned to the incoming wavelength by modifying the morphology of the nanoparticle. For solid metal nanoparticles, spherical shapes set up an SPR along the transverse direction of polarized light. The same transverse band (near the blue region of the spectrum) is also seen for gold nanorods when the incident light interacts with the long axis of the rod. When light interacts with the long axis of nanorods the longitudinal band closer to the infrared can be observed and is quite strong. Higher aspect ratios further red shift the longitudinal band of the absorption of the nanoparticles, thus making long narrow rods of metal quite suitable for infrared light absorption, and hence hyperthermia. (See Fig. 17) The dielectric constant is a measure of electric polarizability of a material. Changes to the dielectric constant surrounding a nanoparticle can shift result in the SPR that are proportional to the changes in the refractive index of the surrounding media. An example would be a shift in the SPR of gold nanorods dispersed in a saline solution as compared to gold nanorods dispersed in pure water. In addition, the SPR shifts linearly with increasing aspect ratios. Another important component of the SPR of nanoparticles that can generate hyperthermia is the breadth of the linewidth since linewidth is inversely proportional to the lifetime of the plasmon and narrow linewidths are sensitive to changes in the dielectric constant of the surrounding media [95].

Specifically for a suspension of gold nanoparticles, the change in temperature due to photoexcitation can be approximated by $\Delta T \propto \frac{I_{o}\left(1-10^{-A_{\lambda}}\right)}{\sigma[A u] C_{p} \ell}$ where $\Delta \mathrm{T}$ is change in 
A: Nanospheres
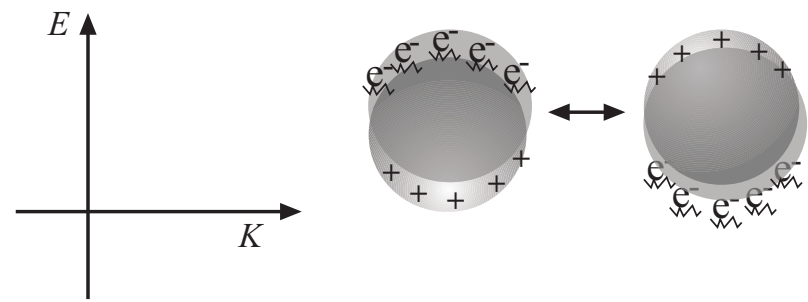

B: Nanorods
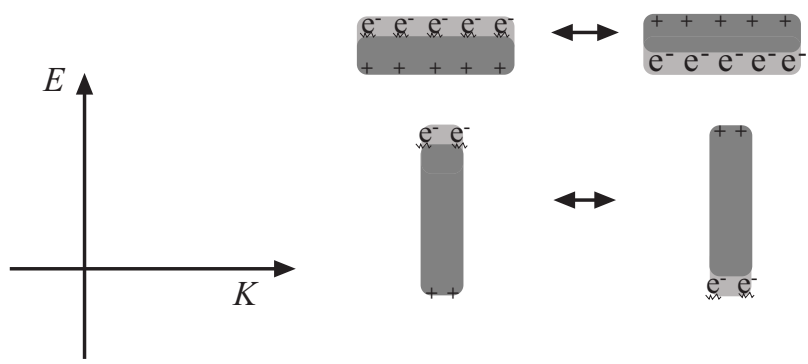
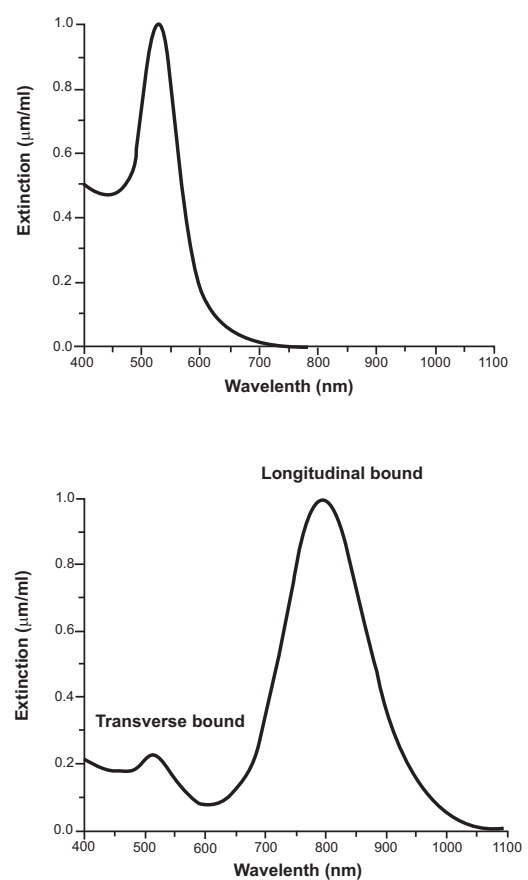

Fig. (17). The longitudinal and transverse SPR peaks of spherical and rod-shaped nanoparticles. Reproduced from [105].

temperature, $I_{o}$ is laser intensity, $\sigma$ is laser spot size, $\mathrm{A}_{\lambda}$ is the absorbance of the sample, $[\mathrm{Au}]$ is the concentration of gold, $\mathrm{C}_{\mathrm{p}}$ is the heat capacity of the solution, and $\ell$ is the optical path length of the solution. The efficiency of heat transduction of the suspended nanoparticles may be calculated by $\eta_{T}=\frac{h A\left(T_{\max }-T_{a m b}\right) Q_{o}}{I\left(1-10^{-A_{\lambda}}\right)}$ where $\mathrm{h}$ is the heat transfer coefficient which can be measured, $\mathrm{Q}_{0}$ is the heat flux of the sample without nanoparticles, A is the surface area of the sample, $I$ is the laser intensity, $\mathrm{T}_{\max }$ and $\mathrm{T}_{\mathrm{amb}}$ are the maximum and ambient temperatures of the solution before and after laser application, and $A_{\lambda}$ is the absorbance of the sample [96]. Although described for gold nanoparticles, similar thermodynamic relations hold for carbon nanotubes and other hyperthermia inducing nanoparticle suspensions.

Plasmon-resonance of metal nanoparticles can generate heat by tuning the absorption to an infrared wavelength, where body tissues are transparent to the infrared, we could use. There have been developments in hyperthermia treatments for ablation and drug delivery, mainly using gold nanoshells. Although silver and gold have been used in medicine for millennia, their efficiency has been hindered because they are commonly applied as an ionic salts or spherically-shaped nanoparticles. There are published studies to indicate that not only the size and chemistry, but also the shape of nanoparticles can have profound effects on cell interactions [97-103]. Silver and gold nanoparticles can be grown and the shapes modified from spherical to triangular and hexagonal, hence developing nanoparticles that strongly absorb infrared light. These particles differ from gold and silver nanoshells where a dielectric core material is coated by a thin layer of the metals. For both nanoshells and metal nanoparticles the same physical principle of surface plasmon resonance is employed to generate an energetic state in the metal and release of the energy as heat away from the particle and into the surrounding media. For nanoshells, the thickness of the metal layer allows tunability of the plasmon resonance in the infrared, whereas for the solid metal nanoparticles, the plasmon resonance is tuned by transforming the shape and size of the particles. Fig. (18) shows the color-variations of the stepwise process for making metal particles that absorb infrared light.

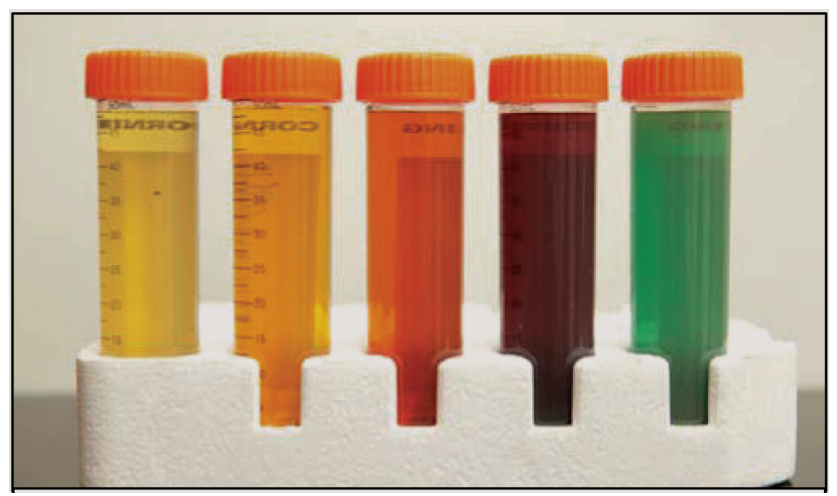

Fig. (18). Color variations of stepwise solutions for producing silver nanoparticles that absorb at $1064 \mathrm{~nm}$. To the left, particles absorb shorter wavelengths and to the right, particles that absorb longer wavelengths.

Typically spherical 'seed' particles of silver absorb around $400 \mathrm{~nm}$ and spherical 'seed' particles of gold around $520 \mathrm{~nm}$. In order to shift absorption into the infrared, the particles must be grown to a larger size (starting seeds are $10 \mathrm{~nm}$ or smaller) and the shape must be modified. The transverse SPR is independent of the aspect ratio of the nanoparticles 


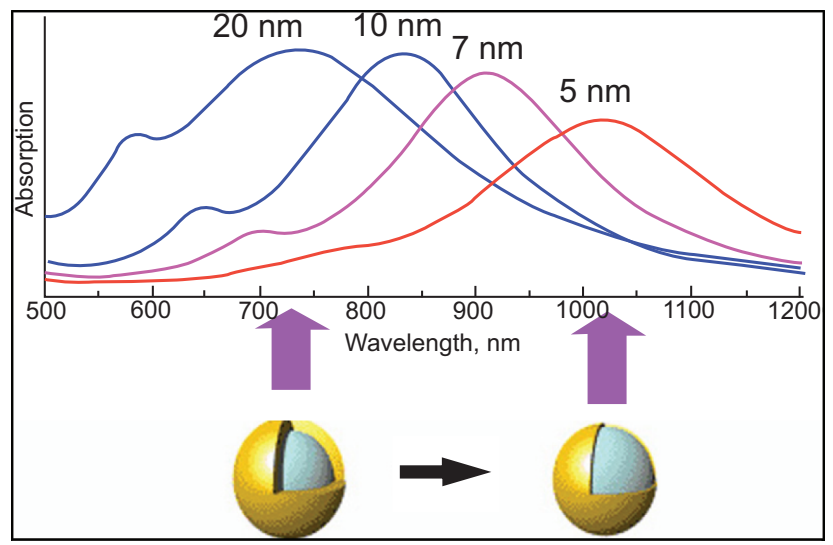

Fig. (19). Red-shifting of the SPR peak of gold nanoshells dependent upon the thickness of the gold shell layer. Reproduced from [56].

and is similar to the SR of the spherical particles, whereas the longitudinal component is dependent upon the anisotropy of the nanoparticles (in the case of nanorods, the longitudinal SPR depends on the aspect ratio). On a plot of optical absorption the transverse SPR peak is closer to the violet (shorter wavelengths) and the longitudinal SPR peak is shifted into the infrared (longer wavelengths) as particle size and anisotropy increases. In addition the longitudinal SPR peak broadens as well as red-shifts because of other particles with different aspect ratios. Nanorods have been used for medical applications in order to induce hyperthermia. A1though nanorods have a substantial longitudinal SPR peak, it is preferred to increase the intensity of the longitudinal SPR peak while decreasing the transverse SPR peak to better optimize metal nanoparticles for IR absorption.

Nanoparticle absorption coefficient is a fundamental parameter for photothermal efficiency. For example, gold nanoparticles have a much higher molar absorption coefficient (1.4E9 $\left.\mathrm{M}^{-1} \mathrm{~cm}^{-1}\right)$ compared to carbon nanotubes $(6.2 \mathrm{E} 6$ $\left.\mathrm{M}^{-1} \mathrm{~cm}^{-1}\right)$ [104]. Kim et al., therefore opted to coat carbon nanotubes with a thin shell of gold in order to increase absorption and also aid in biodispersion of the nanoparticles
[104]. They found a significant increase in the longitudinal and transverse peaks due to the diameter of the nanotubes with the gold shell, as seen in Fig. (19). Wu et al. used gold nanoshells imbedded in liposomes as a proof of principle for a dye release upon infrared stimulation of the lipososme. They found that macroscale hyperthermia does not seem to be the mechanism of liposomal membrane collapse, but rather it is the formation and collapse of microbubbles due to temperature gradients around the nanoparticles. An important finding is that the application of a pulsed (130fs duration, $1 \mathrm{kHz}$ ) laser stimulates the thermal gradients leading to microbubble collapse. On the other hand, the application of continuous wave energy sets up thermal equilibrium with the gold nanoparticles and the surrounding membrane thus inhibiting microbubble formation [105]. Table 3 compares the generation of hyperthermia for some nanoparticle types and relates them to the method of stimulation to induce hyperthermia.

\section{CONCLUSIONS}

One of the major challenges of clinically relevant HIPEC is to better localize chemotherapeutic agents, but this could potentially be overcome by the use of nanoparticles to localize hyperthermia to diseased tissue. Chemical functionalization can aid in localizing nanoparticles and mechanisms for stimulating the nanoparticles to induce hyperthermia include clinically used infrared light, radiofrequency and alternating magnetic fields. The three main types of nanoparticles currently being explored include carbon nanotubes, metal and magnetic nanoparticles. The mechanism of stimulation for hyperthermia in conjunction with the chosen nanoparticle affects the efficiency of hyperthermia. Currently SWNT are more efficient than gold nanoshells when stimulated by infrared light, but SWNT stimulated by radiofrequency offers a much higher temperature increase. Many studies using nanoparticles for hyperthermia are exploring high temperature ablation, but the same nanoparticles and mechanisms can also be very beneficial to generate mild hyperthermia for delivery of chemotherapeutic agents. Thermal ablation using the principle of the nanobomb to generate rapid temperature increases and possible cavitation of the tumor mass must be carefully evaluated. Although the thermal mechanisms are

Table 3. Comparison of Different Types of Nanoparticles and the Heat they can Generate Dependent Upon the Method of Stimulation and Concentration

\begin{tabular}{|c|c|c|c|c|}
\hline Nanoparticle type & $\begin{array}{c}\text { Method of Hyperthermia } \\
\text { Generation }\end{array}$ & $\begin{array}{c}\text { Concen-tration } \\
(\mathbf{m g} / \mathbf{L})\end{array}$ & $\begin{array}{c}\text { Temperature Increase } \\
\text { (deg. C/s) }\end{array}$ & Author \\
\hline \hline Fe3O4 & $\begin{array}{c}\text { Mag. Field } \\
\text { 375kHz, 4kA/m }\end{array}$ & 1000 & 0.053 & Purushotham, et al. \\
\hline CoMoCAT SWNT & $\begin{array}{c}\text { Radiofrequency } \\
13.56 \mathrm{MHz}, 600 \mathrm{~W}\end{array}$ & 500 & 8 & Gannon, et al. \\
\hline SWNT & $\begin{array}{c}\text { Infrared light } \\
808 \mathrm{~nm}, 1.4 \mathrm{~W} / \mathrm{cm} 2\end{array}$ & 25 & 0.375 & Kam, et al. \\
\hline MWNT & $\begin{array}{l}\text { Infrared light } \\
1064 \mathrm{~nm}, 3.84 \mathrm{~W} / \mathrm{cm} 2\end{array}$ & 100 & 0.625 & Levi-Polyachenko, et al. \\
\hline Au Nanoshells & Infrared light & & & O'Neal, et al. \\
\hline
\end{tabular}


beneficial, disruption of the tumor architecture may not be optimal as this could lead to dissemination of tumors. Therefore, the use of milder temperatures along with a chemotherapy may be very advantageous for controlling metastatic disease. In the future, it is envisioned that functionalized nanoparticles might be used to target peritoneal disease and that localized hyperthermia could be generated in either an open or closed abdominal procedure. The cellular mechanisms including increased permeability of the cell membrane will allow for maximum drug uptake by tumor cells disseminated from colorectal cancer. The clinical use of nanoparticles might be limited by several regulatory issues. Although it appears as though metal nanoparticles are deemed safe, there is some conflicting toxicological data on whether carbon nanotubes elicit a toxic response. The use of metal coated nanotubes should be explored to better enhance the effectiveness metal nanoparticles to induce hyperthermia, Once the regulatory use issues can be overcome, we expect the mechanism of using mild hyperthermia to enhance drug uptake for peritoneal malignancies to rapidly expand into clinical practice, through testing in clinical trials of HIPEC using nanoparticles.

\section{REFERENCES}

[1] American Cancer Society. Cancer facts and figures 2004. 1599 Clifton Rd. NE, Atlanta, GA, 30329, USA: Amer Can Soc 2004.

[2] International Agency for Research on Cancer. 150 Cours Albert Thomas, 69372 Lyon CEDEX 08, France: World Health Org 2002.

[3] Jemal A, Murray T, Ward E, et al. Cancer statistics. Ca-A Can J Clinicians 2005; 55(1): 10-30.

[4] Levine EA, Stewart JH, Russell GB, Geisinger KR, Loggie BL, Shen P. Cytoreductive surgery and intraperitoneal hyperthermic chemotherapy for peritoneal surface malignancy: Experience with 501 procedures. J Am Coll Surg 2007; 204(5): 943-53.

[5] Oleson JR, Samulski TV, Leopold KA, et al. Sensitivity of hyperthermia trial outcomes to temperature and time - Implications for thermal goals of treatment. Int J Rad Onc Bio Phys 1993; 25(2): $289-97$.

[6] Hildebrandt B, Wust P, Ahlers O, et al. The cellular and molecular basis of hyperthermia. Crit Rev Onc Hematol 2002; 43(1): 33-56.

[7] Sugarbaker PH, Mora JT, Carmignani P, Stuart OA, Yoo D. Update on chemotherapeutic agents utilized for perioperative intraperitoneal chemotherapy. Oncologist 2005; 10(2): 112-22.

[8] Rylander MN, Feng YS, Zhang YJ, et al. Optimizing heat shock protein expression induced by prostate cancer laser therapy through predictive computational models. J Biomed Optics 2006; 11(4).

[9] Sugarbaker PH. How I do it - An instrument to provide containment of intraoperative intraperitoneal chemotherapy with optimized distribution. J Surg Onc 2005; 92(2): 142-6.

[10] Schett G, Steiner CW, Xu Q, Smolen JS, Steiner G. TNF alpha mediates susceptibility to heat-induced apoptosis by protein phosphatase-mediated inhibition of the HSF1/hsp70 stress response. Cell Death Differ 2003; 10(10): 1126-36.

[11] Rossi A, Ciafre S, Balsamo M, Pierimarchi P, Santoro MG. Targeting the heat shock factor 1 by RNA interference: A potent tool to enhance hyperthermochemotherapy efficacy in cervical cancer. Cancer Res 2006; 66(15): 7678-85.

[12] Tu S, Mcstay GP, Boucher LM, Mak T, Beere HM, Green DR. In situ trapping of activated initiator caspases reveals a role for caspase-2 in heat shock-induced apoptosis. Nat Cell Bio 2006; 8(1): 72-U24.

[13] Beere HM. Death versus survival: functional interaction between the apoptotic and stress-inducible heat shock protein pathways. J Clin Invest 2005; 115(10): 2633-9.

[14] Gurbuxani S, Bruey JM, Fromentin A, et al. Selective depletion of inducible HSP70 enhances immunogenicity of rat colon cancer cells. Oncogene 2001; 20(51): 7478-85.

[15] Yavelsky V, Vais O, Piura B, Wolfson M, Rabinovich A, Fraifeld $\mathrm{V}$. The role of Hsp90 in cell response to hyperthermia. J Thermal Biol 2004; 29(7-8): 509-14.
[16] Gabai VL, Zamulaeva IV, Mosin AF, et al. Resistance of Ehrlich tumor cells to apoptosis can be due to accumulation of heat shock proteins. FEBS Lett 1995; 375(1-2): 21-6.

[17] Gabai VL, Kabakov AE. Induction of heat-shock protein synthesis and thermotolerance in EL-4 ascites tumor cells by transient ATP depletion after ischemic stress. Exp Mol Pathol 1994; 60(2): 88-99.

[18] Garrido C, Gurbuxani S, Ravagnan L, Kroemer G. Heat shock proteins: Endogenous modulators of apoptotic cell death. Biochem Biophys Res Commun 2001; 286(3): 433-42.

[19] Kiang JG, Tsokos GC. Heat shock protein $70 \mathrm{kDa}$ : Molecular biology, biochemistry, and physiology. Pharmacol Therapeutics 1998; 80(2): 183-201.

[20] Maroni P, Bendinelli P, Tiberio L, Rovetta F, Piccoletti R, Schiaffonati L. In vivo heat-shock response in the brain: signalling pathway and transcription factor activation. Mol Brain Res 2003; 119(1): 90-9.

[21] Ravagnan L, Gurbuxani S, Susin SA, et al. Heat-shock protein 70 antagonizes apoptosis-inducing factor. Nat Cell Bio 2001; 3(9): 839-43.

[22] Ito A, Honda H, Kobayashi T. Cancer immunotherapy based on intracellular hyperthermia using magnetite nanoparticles: a novel concept of "heat-controlled necrosis" with heat shock protein expression. Can Immunol Immunother 2006; 55(3): 320-8.

[23] Aalinkeel R, Bindukumar B, Reynolds JL, et al. The Dietary bioflavonoid, quercetin, selectively induces apoptosis of Prostate cancer cells by down-regulating the expression of heat shock protein 90. Prostate 2008; 68(16): 1773-89.

[24] Jakubowicz-Gil J, Paduch R, Piersiak T, Glowniak K, Gawron A, Kandefer-Szerszen M. The effect of quercetin on pro-apoptotic activity of cisplatin in HeLa cells. Biochem Pharmacol 2005; 69(9): 1343-50.

[25] Rong Y, Yang EB, Zhang K, Mack P. Quercetin-induced apoptosis in the monoblastoid cell line U937 in vitro and the regulation of heat shock proteins expression. Anticancer Res 2000; 20(6B): 4339-45.

[26] Sharma H, Sen S, Singh N. Molecular pathways in the chemosensitization of cisplatin by quercetin in human head and neck cancer. Can Bio Therapy 2005; 4(9): 949-55.

[27] Wenzel U, Herzog A, Kuntz S, Daniel H. Protein expression profiling identifies molecular targets of quercetin as a major dietary flavonoid in human colon cancer cells. Proteomics 2004; 4(7): 2160-74.

[28] Carmignani L, Gadda F, Gazzano G, et al. High incidence of benign testicular neoplasms diagnosed by ultrasound. J Urol 2003; 170(5): 1783-6.

[29] Averbach AM, Sugarbaker PH. Recurrent intraabdominal cancer with intestinal-obstruction. Int Surg 1995; 80(2): 141-6.

[30] Eggermont AMM, Steller EP, Sugarbaker PH. Laparotomy enhances intraperitoneal tumor-growth and abrogates the antitumor effects of Interleukin-2 and lymphokine-activated killer-cells. Surgery 1987; 102(1): 71-8.

[31] Varban O, Levine EA, Stewart JH, Mccoy TP, Shen P. Outcomes associated with cytoreductive surgery and intraperitoneal hyperthermic chemotherapy in colorectal cancer patients with peritoneal surface disease and hepatic metastases. Cancer 2009; 115(15): 3427-36.

[32] Verwaal VJ, van Ruth S, de Bree E, et al. Randomized trial of cytoreduction and hyperthermic intraperitoneal chemotherapy versus systemic chemotherapy and palliative surgery in patients with peritoneal carcinomatosis of colorectal cancer. J Clin Oncol 2003; 21(20): 3737-43.

[33] Dedrick RL, Flessner MF. Pharmacokinetic problems in peritoneal drug administration: Tissue penetration and surface exposure. J National Cancer Inst 1997; 89(7): 480-7.

[34] Dedrick RL. Interspecies scaling of regional drug delivery. J Pharm Sci 1986; 75(11): 1047-52.

[35] Flessner MF, Fenstermacher JD, Dedrick RL, Blasberg RG. A distributed model of peritoneal-plasma transport - tissue concentration gradients. Am J Physiol 1985; 248(3): F425-F435.

[36] Bartlett DL, Buell JF, Libutti SK, et al. A phase I trial of continuous hyperthermic peritoneal perfusion with tumor necrosis factor and cisplatin in the treatment of peritoneal carcinomatosis. Cancer 1998; 83(10): 2241.

[37] Ozols RF, Young RC, Speyer JL, et al. Phase-1 and pharmacological studies of adriamycin administered intraperitoneally to patients with ovarian-cancer. Cancer Res 1982; 42(10): 4265-9. 
[38] Kuzuya T, Yamauchi M, Ito A, Hasegawa M, Hasegawa T, Nabeshima T. Pharmacokinetic characteristics of 5-fluorouracil and mitomycin-C in intraperitoneal chemotherapy. J Pharm Pharmacol 1994; 46(8): 685-9.

[39] Speyer JL, Collins JM, Dedrick RL, et al. Phase-I and pharmacological studies of 5-fluorouracil administered intraperitoneally. Cancer Res 1980; 40(3): 567-72.

[40] Israel VK, Jiang C, Muggia FM, et al. Intraperitoneal 5-fluoro-2'deoxyuridine (Fudr) and (S)-leucovorin for disease predominantly confined to the peritoneal-cavity - A pharmacokinetic and toxicity study. Cancer Chemother Pharmacol 1995; 37(1-2): 32-8.

[41] Markman M, Brady MF, Spirtos NM, Hanjani P, Rubin SC. Phase II trial of intraperitoneal paclitaxel in carcinoma of the ovary, tube, and peritoneum: A gynecologic oncology group study. J Clin Oncol 1998; 16(8): 2620-4.

[42] Stewart JH, Shen P, Russell G, et al. A phase I trial of oxaliplatin for intraperitoneal hyperthermic chemoperfusion for the treatment of peritoneal surface dissemination from colorectal and appendiceal cancers. Ann Surg Oncol 2008; 15(8): 2137-45.

[43] Stewart JH, Shen P, Levine EA. Translation considerations for hyperthermic intraperitoneal chemotherapy. Curr Probl Cancer 2009; 33(3): 194-202.

[44] Hirsch LR, Gobin AM, Lowery AR, et al. Metal nanoshells. Ann Biomed Eng 2006; 34(1): 15-22.

[45] Shenoy DB, Amiji MA. Poly(ethylene oxide)-modified poly(epsilon-caprolactone) nanoparticles for targeted delivery of tamoxifen in breast cancer. Int J Pharmaceutics 2005; 293(1-2): 261-70.

[46] Reddy LH. Drug delivery to tumours: recent strategies. J Pharm Pharmacol 2005; 57(10): 1231-42.

[47] Portney NG, Ozkan M. Nano-oncology: drug delivery, imaging, and sensing. Anal Bioanal Chem 2006; 384(3): 620-30.

[48] Kroto HW, Heath JR, Obrien SC, Curl RF, Smalley RE. C-60 Buckminsterfullerene. Nature 1985; 318(6042): 162-3.

[49] Ely JL, Emken MR, Accuntius JA, et al. Pure pyrolytic carbon: Preparation and properties of a new material, On-X (R) carbon for mechanical heart valve prostheses. J Heart Valve Dis 1998; 7(6): 626-32.

[50] Goodman SL, Tweden KS, Albrecht RM. Platelet interaction with pyrolytic carbon heart-valve leaflets. J Biomed Mater Res 1996; 32(2): 249-58.

[51] Dresselhaus MS, Dresselhaus G, Charlier JC, Hernandez E. Electronic, thermal and mechanical properties of carbon nanotubes. Philosophical Trans Royal Soc London Series A-Math Phys Eng Sci 2004; 362(1823): 2065-98.

[52] Carrero-Sanchez JC, Elias AL, Mancilla R, et al. Biocompatibility and toxicological studies of carbon nanotubes doped with nitrogen. Nano Lett 2006; 6(8): 1609-16.

[53] Liu JW, Webster S, Carroll DL. Temperature and flow rate of NH3 effects on nitrogen content and doping environments of carbon nanotubes grown by injection CVD method. J Phys Chem B 2005; 109(33): 15769-74.

[54] Misra A, Tyagi PK, Singh MK, Misra DS. FTIR studies of nitrogen doped carbon nanotubes. Diamond Relat Mat 2006; 15(2-3): 385-8.

[55] Xu JF, Xiao M, Czerw R, Carroll DL. Optical limiting and enhanced optical nonlinearity in boron-doped carbon nanotubes. Chem Phys Lett 2004; 389(4-6): 247-50.

[56] Hepplestone SP, Ciavarella AM, Janke C, Srivastava GP. Size and temperature dependence of the specific heat capacity of carbon nanotubes. Surf Sci 2006; 600(18): 3633-6.

[57] Iijima S. Helical microtubules of graphitic carbon. Nature 1991; 354(6348): 56-8.

[58] Mittal JP. Excited-states and electron-transfer reactions of fullerenes. Pure App Chem 1995; 67(1): 103-10.

[59] Sears A, Batra RC. Buckling of multiwalled carbon nanotubes under axial compression. Phys Rev B 2006; 73(8).

[60] Wang X, Sun B, Yang HK. Stability of multi-walled carbon nanotubes under combined bending and axial compression loading. Nanotechnology 2006; 17(3): 815-23.

[61] Kouklin N, Tzolov M, Straus D, Yin A, Xu JM. Infrared absorption properties of carbon nanotubes synthesized by chemical vapor deposition. Appl Phys Lett 2004; 85(19): 4463-5

[62] Torti S, Byrne F, Whelan O, et al. Thermal ablation therapeutics based on CNx multi-walled nanotubes. Int J Nanomed 2007; 2(4).

[63] Kam NWS, O'Connell M, Wisdom JA, Dai HJ. Carbon nanotubes as multifunctional biological transporters and near-infrared agents for selective cancer cell destruction. Proc Natl Acad Sci USA 2005; 102(33): 11600-5.

[64] Menna E, Scorrano G, Maggini M, et al. Shortened single-walled nanotubes functionalized with poly(ethylene glycol): preparation and properties. Arkivoc 2003; 64-73.

[65] Sinani VA, Gheith MK, Yaroslavov AA, et al. Aqueous dispersions of single-wall and multiwall carbon nanotubes with designed amphiphilic polycations. J Am Chem Soc 2005; 127(10): 3463-72.

[66] Tkac J, Ruzgas T. Dispersion of single walled. carbon nanotubes. Comparison of different dispersing strategies for preparation of modified electrodes toward hydrogen peroxide detection. Electrochem Comm 2006; 8(5): 899-903.

[67] Terrones M. Science and technology of the twenty-first century: Synthesis, properties and applications of carbon nanotubes. Ann Rev Mat Res 2003; 33: 419-501.

[68] Belin T, Epron R. Characterization methods of carbon nanotubes: a review. Mat Sci Eng B-Solid State Mat Adv Technol 2005; 119(2): 105-18.

[69] Bandow S, Asaka S, Saito Y, et al. Effect of the growth temperature on the diameter distribution and chirality of single-wall carbon nanotubes. Phys Rev Lett 1998; 80(17): 3779-82.

[70] Saito R, Gruneis A, Samsonidze GG, et al. Optical absorption of graphite and single-wall carbon nanotubes. App Phys A-Mat Sci Process 2004; 78(8): 1099-105.

[71] Bachilo SM, Strano MS, Kittrell C, Hauge RH, Smalley RE, Weisman RB. Structure-assigned optical spectra of single-walled carbon nanotubes. Science 2002; 298(5602): 2361-6.

[72] O'Connell MJ, Bachilo SM, Huffman CB, et al. Band gap fluorescence from individual single-walled carbon nanotubes. Science 2002; 297(5581): 593-6.

[73] Casey A, Farrell GF, McNamara M, Byrne1 HJ, Chambers G. Interaction of carbon nanotubes with sugar complexes. Synth Met 2005; 153(1-3): 357-60.

[74] Maksimenko SA, Slepyan GY, Nemilentsau AM, Shuba MV. Carbon nanotube antenna: Far-field, near-field and thermal-noise properties. Physica E: Low-dim Sys Nanostructures 2008; 40(7): 2360-4.

[75] Dresselhaus MS, Eklund PC. Phonons in carbon nanotubes. Advances Phys 2000; 49(6): 705-814.

[76] Hepplestone SP, Srivastava GP. The intrinsic lifetime of lowfrequency zone-centre phonon modes in silicon nanowires and carbon nanotubes. Appl Surf Sci 2006; 252(21): 7726-9.

[77] Kempa K, Rybczynski J, Huang ZP, et al. Carbon nanotubes as optical antennae. Adv Mat 2007; 19(3): 421-6.

[78] Wang Y, Kempa K, Kimball B, et al. Receiving and transmitting light-like radio waves: Antenna effect in arrays of aligned carbon nanotubes. App Phys Lett 2004; 85(13): 2607-9.

[79] Hanson GW. Fundamental transmitting properties of carbon nanotube antennas. IEEE Trans Antennas Propag 2005; 53(11): 342635 .

[80] Burke PJ, Li SD, Yu Z. Quantitative theory of nanowire and nanotube antenna performance. IEEE Trans Nanotechnol 2006; 5(4): 314-34.

[81] Weissleder R. A clearer vision for in vivo imaging. Nat Biotechnol 2001; 19: 319 .

[82] Braun C, Smirnov S. Why is water blue. J Chemical Educ 1993; 70(8): 612 .

[83] Launay S, Fedorov AG, Joshi Y, Cao A, Ajayan PM. Hybrid micro-nano structured thermal interfaces for pool boiling heat transfer enhancement. Microelectronics J 2006 Nov; 37(11): 1158-64.

[84] Park KJ, Jung D. Enhancement of nucleate boiling heat transfer using carbon nanotubes. Int J Heat Mass Transfer 2007; 50(21-22): 4499-502.

[85] Zhang HL, Chen ZQ. Nanobomb: A potential technique for in vivo imaging and targeted cancer cell destruction. Med Hypotheses 2009; 73(5): 864-5.

[86] Lee Y, Park SY, Kim C, Park TG. Thermally triggered intracellular explosion of volume transition nanogels for necrotic cell death. J Cont Rel 2009; 135(1): 89-95.

[87] Gannon CJ, Cherukuri P, Yakobson BI, et al. Carbon nanotubeenhanced thermal destruction of cancer cells in a noninvasive radiofrequency field. Cancer 2007; 110(12): 2654-65.

[88] Burke A, Ding XF, Singh R, et al. Long-term survival following a single treatment of kidney tumors with multi-walled carbon nanotubes and near-infrared radiation. Proc Natl Acad Sci USA 2009; 106(31): 12897-902. 
[89] Levi-Polyachenko NH, Merkel EJ, Jones BT, Carroll DL, Stewart JH. Rapid photothermal intracellular drug delivery using multiwalled carbon nanotubes. Mol Pharm 2009; 6(4): 1092-9.

[90] Tong L, Zhao Y, Huff TB, Hansen MN, Wei A, Cheng JX. Gold nanorods mediate tumor cell death by compromising membrane integrity. Adv Mat 2007; 19(20): 3136-41.

[91] Liu Z, Chen K, Davis C, et al. Drug delivery with carbon nanotubes for in vivo cancer treatment. Cancer Res 2008; 68(16): 665260.

[92] Liu Z, Cai WB, He LN, et al. In vivo biodistribution and highly efficient tumour targeting of carbon nanotubes in mice. Nat Nanotechnol 2007; 2(1): 47-52.

[93] Zhang XK, Meng LJ, Lu QG, Fei ZF, Dyson PJ. Targeted delivery and controlled release of doxorubicin to cancer cells using modified single wall carbon nanotubes. Biomaterials 2009; 30(30): 6041-7.

[94] Purushotham S, Ramanujan RV. Thermoresponsive magnetic composite nanomaterials for multimodal cancer therapy. Acta Biomat 2010; 6(2): 502-10

[95] Jain PK, Lee KS, El-Sayed IH, El-Sayed MA. Calculated absorption and scattering properties of gold nanoparticles of different size, shape, and composition: Applications in biological imaging and biomedicine. J Phys Chem B 2006; 110(14): 7238-48.

[96] Roper DK, Ahn W, Hoepfner M. Microscale heat transfer transduced by surface plasmon resonant gold nanoparticles. J Phys Chem C 2007; 111(9): 3636-41.

[97] Brown SC, Kamal M, Nasreen N, et al. Influence of shape, adhesion and simulated lung mechanics on amorphous silica nanoparticle toxicity. Adv Powder Technol 2007; 18(1): 69-79.
[98] Jahnen-Dechent W, Simon U. Function follows form: shape complementarity and nanoparticle toxicity. Nanomedicine 2008; 3(5): 601-3.

[99] Powers KW, Palazuelos M, Moudgil BM, Roberts SM. Characterization of the size, shape, and state of dispersion of nanoparticles for toxicological studies. Nanotoxicology 2007; 1(1): 42-51.

[100] Wang SG, Lu WT, Tovmachenko O, Rai US, Yu HT, Ray PC. Challenge in understanding size and shape dependent toxicity of gold nanomaterials in human skin keratinocytes. Chem Phys Lett 2008; 463(1-3): 145-9.

[101] Decuzzi P, Pasqualini R, Arap W, Ferrari M. Intravascular delivery of particulate systems: Does geometry really matter? Pharm Res 2009; 26(1): 235-43.

[102] Decuzzi P, Lee S, Decuzzi M, Ferrari M. Adhesion of microfabricated particles on vascular endothelium: A parametric analysis. Ann Biomed Eng 2004; 32(6): 793-802.

[103] Serda RE, Go JH, Bhavane RC, et al. The association of silicon microparticles with endothelial cells in drug delivery to the vasculature. Biomaterials 2009; 30(13): 2440-8

[104] Kim JW, Galanzha EI, Shashkov EV, Moon HM, Zharov VP. Golden carbon nanotubes as multimodal photoacoustic and photothermal high-contrast molecular agents. Nat Nanotechnol 2009; 4(10): 688-94.

[105] Wu GH, Milkhailovsky A, Khant HA, Fu C, Chiu W, Zasadzinski JA. Remotely triggered liposome release by near-infrared light absorption via hollow gold nanoshells. J Am Chem Soc 2008; 130(26): 8175-7.

Received: May 15, 2010

(C) Levi-Polyachenko and Stewart; Licensee Bentham Open.

This is an open access article licensed under the terms of the Creative Commons Attribution Non-Commercial License (http://creativecommons.org/licenses/by-nc/3.0/) which permits unrestricted, non-commercial use, distribution and reproduction in any medium, provided the work is properly cited. 